\title{
The archaeal triphosphate tunnel metalloenzyme SaTTM defines structural determinants for the diverse activities in the CYTH protein family
}

\author{
Marian S. Vogt ${ }^{1}$, Roi R. Ngouoko Nguepbeu ${ }^{1}$, Michael K. F. Mohr ${ }^{2}$, Sonja-Verena Albers ${ }^{3}$, \\ Lars-Oliver Essen ${ }^{1,4 *}$, and Ankan Banerjee ${ }^{1,5 *}$
}

${ }^{1}$ Department of Chemistry, Philipps-Universität Marburg, Hans-Meerwein-Str. 4, D-35032 Marburg, Germany.

${ }^{2}$ Institute of Pharmaceutical Sciences, Albert-Ludwigs-Universität Freiburg, Albertstr. 25, D79104 Freiburg, Germany

${ }^{3}$ Institute of Biology II, Molecular Biology of Archaea, Albert-Ludwigs-Universität Freiburg, Schänzlestrasse 1, D-79104 Freiburg, Germany.

${ }^{4}$ Center for Synthetic Microbiology, Philipps-Universität Marburg, Hans-Meerwein-Str. 4 D35032 Marburg

${ }^{5}$ Department of Genetics, Philipps-Universität Marburg, Karl-Von-Frisch-Str 10, D-35043 Marburg, Germany.

${ }^{*}$ Corresponding author: Ankan Banerjee (banerjee@staff.uni-marburg.de) and Lars-Oliver Essen (essen@chemie.uni-marburg.de)

Running title: Archaeal CYTH proteins are triphosphatase

Keywords: CYTH enzymes, triphosphatase tunnel metalloenzyme, two-metal ion mechanism, sequence similarity network, protein structure evolution

Abbreviations: Pi orthophosphate, PPi pyrophosphate, PPPi triphosphate, CYTH CyaBThiamine triphosphatase 


\section{Major highlights}

- CyaB-like class IV adenylyl cyclase homologs in archaea are triphosphatases.

- The co-crystal structure of SaTTM in sulfate and triphosphate bound state revealed conformational transition of the TTM tunnel during catalysis.

- Atomic insights into TTM inhibition by calcium and pyrophosphate.

- In silico and structure-function analysis revealed the molecular determinant for functional diversification among CYTH proteins. 


\begin{abstract}
CYTH is a large protein superfamily that is conserved in all three domains of life with its unique triphosphate tunnel metalloenzyme (TTM) fold. Besides phosphatase functions, e.g. as RNA triphosphatase, inorganic polyphosphatase or thiamine triphosphatase, some CYTH orthologs cyclize nucleotide triphosphates to 3',5'-cyclic nucleotides. So far, archaeal CYTH proteins are annotated as adenylyl cyclases although experimental evidence is lacking. To address this gap, we characterized a CYTH ortholog, SaTTM, from the crenarchaeote Sulfolobus acidocaldarius. Our initial in silico studies suggested a close relationship between archaeal CYTH enzymes and class IV adenylyl cyclases compared to the other CYTH-subclasses, but biochemical data showed no cyclic nucleotide production. Instead, our structural and functional analyses show a classical TTM behavior. The $\mathrm{Ca}^{2+}$-inhibited Michaelis complex indicates a two-metal ion reaction mechanism analogous to other TTMs. Different co-crystal structures of SaTTM further reveal conformational dynamics in SaTTM, let us to assume feedback inhibition in TTMs due to tunnel closure in the product state. Combining our structural insights with sequence-similarity network based in silico analysis, we further set out a firm molecular basis for distinguishing CYTH orthologs with phosphatase activities from class IV adenylyl cyclases.
\end{abstract}




\section{Introduction}

Bacterial CyaB-like class IV adenylyl cyclases (AC-IV) and mammalian thiamine triphosphatases (ThTPase) are founding members of the CYTH-like domain superfamily (1). CYTH enzymes are found in all three domains of life and can be traced back to the last common ancestor, which makes them to appealing targets for studying protein evolution (1). Beside CyaB and ThTPases, the CYTH-like domain superfamily comprises inorganic triphosphatases $(2,3)$, which together are wrapped up in a CYTH domain subfamily, and Cet1like RNA-triphosphatases that have their own subfamily of $m R N A$ triphosphatase Cet1-like enzymes within the superfamily (4).

The characteristic structural feature of CYTH enzymes is an 8-stranded $\beta$-barrel tunnel architecture, termed triphosphate tunnel metalloenzyme (TTM) fold, which was first found in the crystal structure of the fungal Cet1 RNA triphosphatase $(4,5)$. The hallmark of CYTH enzymes is an $\mathrm{N}$-terminal ExExK motif that is involved in metal ion coordination and substrate binding (3). The opposing acidic and basic patches shape the substrate binding tunnel. While the overall coordination of the triphosphate itself is very similar among CYTH enzymes, the directionality of asymmetric organic substrates such as triphosphate nucleotides or thiamine triphosphate within the tunnel in fact determines catalytic specificity (3). For triphosphatases and ThTPases, the organic moiety points towards a C-terminal helix, termed plug helix $(3,6)$. Such enzymes catalyze the hydrolysis of the triphosphate by a two-metal ion mechanism using metal 1 to establish the catalytically competent binding of the triphosphate moiety and metal 2 to position and activate a water for nucleophilic attack onto the $\mathrm{y}$-phosphate moiety (3). In the case of triphosphatases, a pyrophosphate and an orthophosphate are produced by hydrolysis of the $\beta-\gamma$ phosphoanhydride bond. The situation for AC-IV enzymes in the CYTH superfamily is different. Here, the directionality of the organic moiety binding within the tunnel fold is inverted causing a reversed placement of the $\alpha$ - and $y$-phosphates within the binding tunnel (7). By comparing AC-IV with already described AC-classes, a general two-metal ion mechanism was suggested for the cyclization of ATP to 3',5'-cAMP using the second metal to lower the activation energy (7-10).

The founding members of the CYTH superfamily are involved either in mammalian thiamine triphosphate metabolism or bacterial signal transduction via 3',5'-cyclic nucleotides. Some members of the CYTH superfamily are parts of multi-domain proteins by being fused to HD hydrolase, exopolyphosphatase, nucleotidyl kinase, or CHAD domains (1). It was postulated that CYTH protein might play a central role at the interface between nucleotide and phosphate metabolism $(1,11)$. Archaeal representatives encode at least one copy of a CYTH ortholog in their genomes, which are generally annotated as adenylyl cyclases. The presence of 3',5'cAMP is described for a few archaeal species indicating a role in starvation and cell cycle (12, 13). In search for a potential nucleotidyl cyclase in the crenarchaeote Sulfolobus acidocaldarius, we identified Saci_0718, a CYTH superfamily protein, annotated as CyaB-like class IV adenylyl cyclase. Although the substrate binding mode and the hydrolysis mechanisms differ between triphosphatases and CyaB (3), at the sequence level, Saci_0718 shares $\sim 29 \%$ identity with the Yersinia pestis cyclase CyaB and with the inorganic triphosphatase from Clostridium thermocellum.

Here, we have performed a structure-function analysis for the only ortholog of a CYTH enzyme in Sulfolobus acidocaldarius, SaTTM. SaTTM is a triphosphatase. Its structures in sulfate and substrate (triphosphate and ATP) bound states revealed conformational dynamics during catalysis. We trapped the Michaelis-complex of the enzyme in its calcium-inhibited state that established TTM phosphatases follow a two-metal ion mechanism. The product-bound (PPi) co-crystal structure set the molecular basis of feedback inhibition in TTM. Our structurefunction analysis identified the important role of ordered water molecules for substrate binding. Our in-depth sequence similarity network separated CYTH superfamily into various clusters according to their function. Taken together, a comparative structural and bioinformatic analysis of the CYTH proteins led us to identify motifs that represent molecular determinants underpinning the different functions as adenylyl cyclase and phosphatase within the CYTH enzymes. 


\section{Results}

\section{Archaeal CYTH proteins are functionally diverged from CyaB-like class IV adenylyI cyclases}

To date, the CYTH-like domain superfamily (IPR033469) comprises 41000 enzymes from all three domains of life divided in two subfamilies, the smaller mRNA triphosphatase Cet1-like (IPR004206) and the bigger subfamily of CYTH domain proteins (IPR023577) including adenylyl cyclases, ThTPases, and inorganic tri- or polyphosphatases (also known as triphosphatase tunnel metalloenzymes or TTMs). The discrimination between Cet1-like and CYTH enzymes is also consistent within the Pfam database (mRNA_triPase: PF02940 and CYTH: PF01928). Hence, we aimed to obtain a detailed understanding of the CYTH family by a detailed bioanalytical analysis combined with structural insights, as the functional annotations of CYTH enzymes is still vague and misleading among TTMs and adenylyl cyclases.

In order to restrict our studies on an unambiguous assignment, we chose the Pfam family CYTH (PF01928) as the least common denominator for our analysis. As stated above, this protein family contains enzymes with known functions as TTMs, AC-IVs, and ThTPases. We therefore performed a systematic sequence similarity network (SSN) analysis of the CYTH superfamily PF01928 using EFI-EST (14). The network generated with an E-value of $10^{-20}$ against the CYTH-domain boundaries for 38246 sequences, clustered to 4128 nodes with pairwise sequence identities of $>40 \%$ within the nodes, which are connected by a total of 121791 edges. This SSN analysis covering all members of the CYTH enzymes of PF01928 showed ten major distinct clusters (Fig. 1). Among these clusters, three of them (cluster 1, 4 and 7) comprise members adopting a multi-domain architecture, while the length histograms for the remaining seven clusters are in the expected range of $\sim 160-200$ amino acids for single domain proteins (Fig. S7A). For example, cluster 1 contains YgiF from Escherichia coli, which possesses a two-domain architecture with an N-terminal CYTH and a C-terminal CHAD domain (PF05235) (3). Similar modular architectures including the CHAD-domain can be found in cluster 4 , which does not contain any structurally described homologs and whose members occur mostly in actinobacteria. The additional domain in cluster 7, whose members are exclusively found in Viridiplantae and Amoebozoa, is a phosphoribulokinase domain (PF00485).

Interestingly, the SSN analysis discriminates the cyaB-like class IV adenylyl cyclase $(7,15)$ (cluster 10) from other triphosphatases. Cluster 10 is a relatively small cluster within the SSN by comprising only 141 orthologs of bacterial origin. Like AC-IV, the ThTPases form a separate cluster, cluster 8 , that is distinct from other triphosphatases. The key molecular determinant of ThTPase was reported previously $(3,6)$. The enzymes described as inorganic triphosphatases are distributed among different clusters. NeuTTM and CthTTM were found in cluster 2, TTM3 from Arabidopsis thaliana is a member of cluster $9(3,16,17)$. The two other described enzymes from $A$. thaliana (TTM1 and TTM2) are in cluster 7 and interestingly they utilize pyrophosphate and not triphosphate (18). AtTTM1 and AtTTM2 does not possess the TTM-signature motifs required for catalysis (Table S1). In cluster 5 , unpublished structures annotated before as adenylyl cyclase from Bacillus anthracis and B. halodurans can be found. A member of this cluster from Staphylococcus aureus has further been described to be incompetent in cAMP formation and to be distinct from class IV adenylyl cylases (19). Cluster 3 contains orthologs of mostly archaeal origin from Pyrococcus furiosus and $P$. horikoshii, as well as Saci_0718 (Uniprot: Q4JAT2). The SSN analysis clearly indicating that the archaeal CYTH enzymes are functionally diverse from CyaB-like class IV adenylyl cyclases.

\section{Sulfolobus acidocaldarius CYTH enzyme is a triphosphatase tunnel metalloenzyme}

To gain in depth biochemical and structural insights into this protein, we heterologously overproduced a C-terminal His 6 -tagged variant of Saci_0718 in Escherichia coli. The recombinant protein was purified to homogeneity using an initial heat step followed by IMAC and subsequent size exclusion chromatography as a polishing step. The enzyme formed a dimer in solution corresponding to $56 \mathrm{kDa}$ compared to standards (Fig. S1). Dimerization 
behavior is typical among other CYTH proteins (11). The first ambiguity to be resolved was determination of its substrate preference and the nature of its hydrolysis products. Initially, we tested its activity against ATP using $\mathrm{Mg}^{2+}$ as cofactor at $75^{\circ} \mathrm{C}$ and the reaction product analyzed by HPLC (Fig. S2A). This experiment clearly showed that the enzyme is capable to hydrolyze ATP to ADP and Pi without any formation of CAMP. Saci_0718 showed no base specificity during its phosphohydrolase reaction and is able to utilize both ATP or GTP with similar efficiency (Fig. 2A). As the reaction products are diphosphate nucleosides and not (c)AMP/GMP, we used non-hydrolysable analogs of ATP, AMPCPP and AMPPCP, to identify the nucleophilic attack site (Fig. S2B). It shows that Saci_0718 acts on the terminal phosphate of ATP, as the enzyme was active on AMPCPP but no phosphate release was observed for AMPPCP.

Next, we used triphosphate (PPPi) as substrate. Under the conditions outlined before Saci_0718 is $\sim 19$ times more active compared to NTP as substrate. The result is consistent with the previous reports of tunnel metalloenzymes $(2,3)$. We also observed that the enzyme is able to hydrolyze higher polyphosphates like tetraphosphate with final formation of pyrophosphate and phosphate (Fig. S3). As triphosphate seems to be the preferred substrate, we named Saci_0718 SaTTM ( $\underline{\text { S. a }}$ acidocaldarius triphosphate tunnel metalloenzyme). The optimal assay conditions were observed at a basic $\mathrm{pH} 8.6$ at $75^{\circ} \mathrm{C}$ using $\mathrm{Mg}^{2+}$ as a cofactor, while $\mathrm{Zn}^{2+}, \mathrm{Mn}^{2+}$, and $\mathrm{Ni}^{2+}$ could be used as weaker cofactor alternatives. Similar to the metal ion chelator EDTA, calcium exerted an inhibitory effect on phosphatase activity (Fig. 2B-C). At optimal conditions, kinetic measurement revealed a classical Michaelis-Menten behavior with a $K_{m}$ of $40.95 \mu \mathrm{M}$ and a $V_{\max }$ of $29.67 \mu \mathrm{M} \mathrm{s}^{-1}$. This shows a highly efficient catalysis performed by SaTTM of $1.45 \times 10^{8} \mathrm{~s}^{-1} \mathrm{M}^{-1}$ close to the diffusion limit and a turnover rate (5934 $\left.\mathrm{s}^{-1}\right)$, which is in the range of untagged NeuTTM $\left(7900 \mathrm{~s}^{-1}\right)(16)$.

\section{Crystal structure of the SaTTM dimer}

For structural information, we crystallized SaTTM in different catalytically relevant complexes. Initial attempts of producing diffraction quality crystals using apo enzyme were unsuccessful. Only by adding ATP as ligand, diffraction quality crystals were obtained, indicating that SaTTM is highly flexible in solution and stabilized upon substrate binding. Orthorhombic crystals of SaTTM in its different catalytic states were obtained after a week at $4^{\circ} \mathrm{C}$ that diffracted to 1.75 2.3 A resolution. For structure determination, Pyrococcus horikoshii OT3 PH1819 (PDB entry 2EEN) was used as search model in molecular replacement. SaTTM was crystallized as a relaxed homodimer (Fig. 3A), bound with two sulfate anions instead of the ATP that was included in co-crystallization. Of note, a solution structure of mouse thiamine triphosphatase (PDB 2JMU) reported a similarly relaxed conformation. The open state of SaTTM was crystallized in space group $P 4{ }_{1} 2{ }_{1}$ with one monomer per asymmetric unit. The polypeptide is defined by electron density for R6-A176, but interrupted for P44-R49 and Q73-R80 by missing density. The general topology of SaTTM is $\beta 1-\alpha 1-\beta 2-\beta 3-\beta 4-\beta 5-\alpha 2-\beta 6-\beta 7-\beta 8-\alpha 3-\beta 9-\alpha 4$. The dimerization of SaTTM was also found in the crystal structure formed by two symmetry mates. PDBePISA revealed that the dimer interface covered $875 \AA^{2}$ with a CSS score of 0.32 and accounts for $8.5 \%$ of the total solvent-accessible area of one protomer (20). The dimerization is mainly established by hydrophobic interactions of residues from $\beta 3, \beta 4, \beta 5$, and $\alpha 2$ and salt bridges between $\mathrm{K} 99$ from one protomer with $\mathrm{E} 81$ from the other protomer. The C-terminal $\alpha 4$ plug helix blocks the tunnel entry from one side. It was previously reported that this plug helix plays a major role in determining substrate preference (2).

\section{The catalytic ensemble of SaTTM}

Next, we aimed to trap the Michaelis complex of SaTTM, for which we co-crystallized the enzyme together with PPPi or ATP, and the respective cofactors $\mathrm{Mg}^{2+}$ or $\mathrm{Ca}^{2+}$ at $4{ }^{\circ} \mathrm{C}$. Substrate-bound states of SaTTM crystallized in a closed tunnel conformation, highlighting the structural rearrangement upon ligand binding (Fig. 3B). This supports the previous notion that CYTH enzymes are highly flexible and can breathe during their catalytic cycle $(6,17)$. In all states but the open state, a closed tunnel conformation including the missing densities of 
P44-R49 and Q73-R80 from the open state is observed, providing a continuous density map throughout the polypeptide.

As shown for AtTTM3 (3), we observed electron density in the PPPi.Mg ${ }^{2+}$ state for just one metal ion octahedrally coordinated by PPPi, E7, and E135 (Fig. 4A and S4A), while the second ion necessary for water activation was missing (Fig. S5). When using a complete PPPi molecule during refinements, we found higher B-factors for the $\gamma$-phosphate. Therefore, the molecule was split into $\mathrm{PPi}$ and $\gamma-\mathrm{Pi}$ and occupancies were separately refined. This revealed that only $76 \%$ of the substrate binding site were occupied with $\gamma$-phosphates, suggesting a slow turnover of the triphosphate in crystallo.

The PPPi.Ca ${ }^{2+}$ state (Fig. 4B) revealed not only metal ion 1, but also the water-activating position of metal ion 2 site present in the electron density. Two $\mathrm{Ca}^{2+}$ ions are coordinated by PPPi, E5, E7, and E137 (Fig. S4B), thereby positioning a water molecule in an inline-attack position $3.2 \AA$ away from the $\gamma$-phosphate phosphorous as observed for the E. coli YgiF.PPPi states (PDB: 5A60, 5A61). Here, no differences of $\gamma$-phosphate B-factors and occupancies were observed, indicating no hydrolysis during crystallization, which is in line with activity tests in the presence of $\mathrm{Ca}^{2+}$ (Fig. 2C). As SaTTM catalyzes asymmetrical cleavage of a symmetric substrate it is difficult to judge the directionality of the substrate, a prerequisite for firm mechanistic conclusions. Hence, we solved the ATP-bound form of SaTTM in the presence of $\mathrm{Ca}^{2+}$ ions. The SaTTM.ATP state revealed the adenosine base on the side of the plug helix $\alpha 4$, defining the orientation of the triphosphate moiety. It also showed that the catalytic mechanism of SaTTM follows a classical inorganic triphosphatase, but not an AC-IV, providing the structural base of TTM function (Fig. 4C). Upon the structural and biochemical confirmation of SaTTM's inability to use calcium as reaction-competent cofactor we wondered how $\mathrm{Ca}^{2+}$ competes with $\mathrm{Mg}^{2+}$. Hence, we performed a titration experiment with increasing concentrations of calcium on a magnesium-catalyzed reaction (Fig. S6A). As expected, we observed at equimolar concentrations a highly reduced activity of SaTTM using PPPi as substrate, and almost no turnover with 5 -fold excess of the inhibiting metal ion, indicating that calcium is a potent inhibitor of TTM.

For comparison with the product state, we determined the crystal structure of SaTTM in complex with pyrophosphate (Fig. 4D). As the Michaelis complex, the post catalytic state appeared to have the same closed tunnel conformation (Fig. S6). By using the superimposed triphosphate state, the two phosphates can be assigned to the $\alpha$-and $\beta$-positions complexing the calcium ion at metal 1 position (Fig. 4D). Three water molecules occupy the positions corresponding to the oxygens from the substrate's $\gamma$-phosphate. The product bound state clearly suggests an inhibitory effect of pyrophosphate on TTM activity and to confirm this notion we performed another titration-inhibition experiment (Fig. S6B). The activity of SaTTM was rapidly decreased and already halved when using a ten-thousandth of the substrate concentration. While this effect plateaus until equimolar concentrations, the inhibition upon tenfold excess is amplified and with 100 -fold excess the enzyme activity was completely abolished. The tunnel closure upon product binding and the enzyme-titration indicates a feedback inhibition mechanism in TTMs.

\section{Role of ordered water molecule in substrate binding and catalysis}

Interestingly, during SSN analysis we found at a less stringent alignment score of $10^{-15}$ that CYTH enzyme orthologs from cluster 3 (including SaTTM) and cluster 10 (including CyaB) belong still to the same cluster. This suggests generally higher sequence and structural similarity between these CyaB and SaTTM-like enzymes compared to other TTM subfamilies, while the triphosphatase-like catalytic mechanism of SaTTM is apparently shared with CYTH enzyme orthologs already well separated at less stringent thresholds. To find a structural rationalization for this phenomenon, we compared the substrate bound states of $Y p C y a B$, AtTTM, and SaTTM (Fig. 5A-B). We identified two water molecules, which are apparently prerequisites for substrate binding, as they occur in all known structures of the CYTH superfamily. These waters are located oppositely to the metal ions and directly hydrogenbonded to the $\alpha$ - and $\beta$-phosphate, hence termed as $\alpha$ - and $\beta$-water (Fig. 5A). While $\beta$-water 
in SaTTM and YpCyaB made a bidentate contact with the DxY motif, this interaction is absent in AtTTM due to a slightly moved water and an NxF motif. Here, the asparagine is $4 \AA$ away and the phenylalanine lacks the ability to establish a hydrogen bond. This $\beta$-water establishes a hydrogen bond with R52 on $\beta 3$, explaining the well-ordered $\beta$-water in AtTTM (Fig. 5B). The deviations in substrate coordination can also be observed on the metal-ion binding side. While SaTTM and YpCyaB share the same arrangement by shaping the binding pocket in close proximity to the $\alpha$-phosphate using a combination of two conserved aromatic residues (Y168/173 and F133/134), the situation in AtTTM is different. Here, a salt bridge ensemble of E167 and K200 is used for direct electrostatic interaction with the $\gamma$-phosphate. As we observed this highly similar binding mode of $\alpha$ - and $\beta$-phosphates in SaTTM and YpCyaB, we wondered about the impact of these residues on enzyme activity. Hence, we mutated the DxY motif and the central tyrosine $\mathrm{Y} 168$, as well as E135 as a dead mutant control due to its central role in metal 1 binding (Fig. 5C). As hypothesized, the SaTTM D38A and Y40A mutants showed reduced activity compared to the wild type. Intuitively, less impact on the catalysis was observed for the conservative $\mathrm{D} 38 \mathrm{~N}$ and Y40F mutants compared to the alanine mutants, as similar hydrogen bond formation is still possible in the asparagine variant, and in the phenylalanine variant we still have the aspartate for $\beta$-water coordination. The double mutant had an accumulating effect with less than $10 \%$ of wild type activity, strengthening the importance of the DxY motif in coordinating properly the water-substrate complex for catalysis. Interestingly, the Y168A mutant showed a twofold turnover rate compared to the wild type enzyme, while the corresponding K200A mutant in AtTTM mutant showed reduced activity (3). These residues are part of the plug helix, a structural element that plays a critical role in substrate preference and enzyme activity (2).

\section{Discussion}

\section{Structural signature that defines versatile CYTH function}

Decades of study on CYTH containing proteins from the protein family PF01978 established the catalytic mechanisms. However, due to high sequence similarities between different isofunctional subclusters it proved hard to assign concrete functions to uncharacterized family members. We aimed to integrate our newly gained structural insights with our findings from the sequence similarity network and already known CYTH enzymes to establish a detailed understanding about their versatile enzyme activities. The directionality of substrate binding is a major mechanistic determinant on the obtained reaction product when comparing TTMs with AC-IVs (3). As already pointed out, our SSN analysis with a slightly less stringent alignment scores in the SSN merged the AC-IV-specific cluster with the SaTTM cluster. Also, SaTTM shared $\sim 29 \%$ identity with both TTMs and AC-IVs, so it is difficult to annotate these conserved enzymes solely on sequence similarity, as the function-specific features of CYTH enzymes have not been well defined. Our cluster analysis of the CYTH superfamily SSN identifies three key motifs that enable us to predict functions for all family members (Fig. 6, Table S1). According to our analysis, a true AC-IV requires a conserved HF-motif that extends the N-terminal signature ExExK-motif to HFxxxxExExK, a feature that is absent in all other CYTH enzymes. In the crystal structure of YpCyaB the phenylalanine (F5) is involved in $\pi-\pi$ stacking of the adenine base, while the histidine $(\mathrm{H} 4)$ residue stacks to the phenylalanine via cation- $\pi$ interaction, suggesting a key role in binding ATP in the correct orientation. When F5 residues were mutated in AC-IV family members their catalytic activity was drastically reduced (7). In addition, the adenine base stacks to the phenylalanine of the HF-motif within a relatively hydrophobic local environment, but no clear directional contacts like hydrogen bonds are made to the adenine amino group indicating that these AC-IVs act not strictly as adenylyl cyclases. The key HF-motif is absent in the sequence of all other CYTH proteins hence we infer that in the absence of an N-terminal HF-motif the CYTH enzyme function is either TTM or ThTPase.

On the other hand, the W/YxRxR motif defines the ThTPases, as this subfamily has a conserved aromatic residue (W53 in case of mouse ThTPase) that is capable of stacking the 
aromatic thiazole of thiamine. Mutation of this residue reduced the plasticity of the ThTPase (6). Interestingly, we find this motif only in one other subfamily (cluster 7) that contains a bidomain class harboring enzymes of the plant TTM1/2 type, which are "TTMs" with a strong substrate preference for pyrophosphate (18). All other clusters have small amino acid substitution at this position (A54 for SaTTM and S59 for YpCyaB). Two arginine residues (R55 and R57 for mouse ThTPase) are required for interaction with the $\beta$ - and $\gamma$-phosphates of ThTP. In AC-IVs, the first arginine residue in this motif is substituted by a small amino acid (V61 in case of YpCyaB), mostly cysteine, valine or leucine (Fig. S6). Hence, it can be hypothesized that the conserved arginine, which interacts with the $\gamma$-phosphate in TTM/ThTPases, is a gate keeper against NTP binding in the cyclase orientation, as the guanidinium group otherwise sterically clashes with the ribose moiety (Fig. 6). The third characteristic feature is an ExE motif on strand $\beta 8$ close to the C-terminus of CYTH proteins (E135 and E137 for SaTTM). These conserved glutamate (E) residues are required for metal binding. In TTM/ThTPases, the second glutamate residue is required for metal 2 binding, which is strictly substituted to alanine in case of AC-IVs. Although this contradicts the generic binding of a second metal ion, a two-metal AC-IV mechanism was suggested before for this subfamily (7). Taken together, this combined analysis provides a basis to delineate proper functional annotation of all CYTH domain containing orthologs.

\section{Biological role of CYTH}

The CYTH superfamily proteins exist in all kingdom of life and can be traced back to the last common ancestor, but the physiological function of this protein family has largely remained elusive. It has been proposed that members of CYTH superfamily might be involved in the interface of metabolism of phosphoryl compounds and nucleotides. Deletion mutants of the founding member of CYTH protein superfamily showed no significant cellular defects (21). In addition, the unusual enzymatic properties, notably the basic $\mathrm{pH}$ and high temperature optima indicate that CYTH enzymes might hardly play a physiological role under normal growth conditions.

So far, the best characterized CYTH proteins from a functional viewpoint derive from plants. The Arabidopsis TTM3 (AtTTM3) knockout plant showed an anomalous root phenotype, indicating a potential role in root development (22). Although it has been established that plant TTMs act as a polyphosphate hydrolase, recent reports suggest that Brachypodium distachyon and Hippeastrum $x$ hybridum TTM proteins might be able to produce a low amount of cAMP under laboratory conditions $(23,24)$. In our enzyme function-based cluster analysis (Fig. 1) we identified all of the so far characterized plant TTMs were present in the same cluster (cluster 9). As stated above, AtTTM1/2 from cluster 7 are different from classical TTMs, as they lack the signature motifs for triphosphate binding and $\gamma$-phosphate hydrolysis (ExExK and ExE, see Table S1). This cluster still harbors the ThTPase typical W/YxRxR motif that is involved in substrate binding from the metal-opposing site, as well as the described DxY motif required for $\alpha / \beta$-water placement (Fig. 5 and S8). This goes along with the observation that AtTTM2 exhibits pyrophosphatase activity in vitro. Upon their deletion, plants became hypersensitive to both virulent and avirulent pathogens and accumulate elevated levels of sialic acid upon infection (25). On the other hand, AtTTM1 that holds a similar enzyme activity as AtTTM2 was shown to be rather involved in leaf senescence (18). These contrasting findings are food for future studies on the regulatory and metabolic roles of plant TTMs.

The strictly cAMP producing CYTH enzymes, the AC-IVs, form only a small cluster in the whole CYTH sequence similarity network (Fig. 1 cluster 10). The biological role of AC-IV is yet to be established. The seminal work discovering AC-IV in Aeromonas hydrophila showed that the $c y a B$ gene is not expressed under standard growth conditions. However, it can complement the function of another adenylyl cyclase, cyaA, when overproduced in a cya $A$ deletion strain. The cyaB mutant strain had no visible defects and behaved similar to the wild type strain. Cellular cAMP levels were also noted to be unaltered upon deletion under normal growth condition (21). Interestingly, in our SSN analysis we identified that the huge majority of organisms that harbor an AC-IV are (potential) pathogens. Hence it is conceivable to 
envision that these AC-IVs might be repressed during normal growth and play hence no function on cellular cAMP production, but participate during pathogenesis. AC-IV enzymes possess no similarities with other bacterial toxins and are devoid of any signal sequence (21). Clearly, future studies will be required to address how expression of AC-IV enzymes is repressed under normal growth condition and what is their precise role during host infection and pathogen maintenance.

In this study we showed that the CYTH enzyme in crenarchaeote Sulfolobus acidocaldarius previously annotated as adenylyl cyclase is actually a phosphohydrolase of the TTM family. SaTTM prefers inorganic triphosphate substrate over NTPs. Inorganic polyphosphates are considered as energy source readily available for converting di or mono phosphorylated nucleotides to more accessible tri-phosphorylated ones (like ATP), as metal chelating polymers or as buffers for cellular $\mathrm{pH}$ homeostasis (26). In bacteria, polyphosphates are formed by PolyP kinase (PPK), whose deletion mutants are defective in biofilm formation, quorum sensing, motility and other virulent properties (27). Electron dense amorphous PolyP granules were noted in the archaeal counterpart (28-30). PolyP accumulation in archaea is directly linked to metal toxicity (31) and oxidative stress (32) and its production is dependent of inorganic phosphate availability in Methanosarcina mazei (33). The exopolyphosphatase (PPX) gene was identified in Sulfolobales, while the polyP kinase is yet to be identified (34). In a recent study the overproduced $p p x$ gene in Sulfolobus acidocaldarius led to a mutant strain lacking PolyP which was impaired in biofilm formation, motility, archaellum assembly and adhesion to glass surfaces (35). Among extremophiles polyP might play a crucial role in environmental fitness (34). Although the concentration of triphosphates is not known in $S$. acidocaldarius but considering our present finding and previous reports, we envision that TTM in archaea might be directly involved in the polyP metabolism and will indirectly take part in PolyP mediated regulatory processes and oxidative stress response. 


\section{Experimental procedures}

\section{Protein over production and purification}

SaTTM (Saci 0718) ORF amplified from Sulfolobus acidocaldarius DSM 639 genome having an $\mathrm{Ncol}$ and $\overline{B a m H I}$ restriction enzyme sites was cloned into $\mathrm{Ncol} / \mathrm{BamHI}$ digested T7-RNA polymerase based expression plasmid pSA4 (36) in order to produce a pSVA1028 that upon induction with IPTG produce C-terminally His6 fusion of SaTTM. The site directed mutants were produced using 'around-the-horn' PCR of the pSVA1028. The correct DNA sequences were verified by sequencing.

Escherichia coli BL21-Gold (DE3) was used for heterologous overproduction of C-terminal $\mathrm{His}_{6}$ fused SaTTM. Cells were grown in lysogeny broth supplemented with $100 \mu \mathrm{g} / \mathrm{ml}$ ampicillin at $37^{\circ} \mathrm{C}$ until an $\mathrm{OD}_{600}$ of 0.5 . The overexpression of SaTTM was induced by using $0.75 \mathrm{mM}$ IPTG at $18{ }^{\circ} \mathrm{C}$ overnight. Cells from $2 \mathrm{~L}$ culture were harvested $(4000 \mathrm{rpm}$ for 20 min), resuspended in $30 \mathrm{ml}$ lysis buffer $(200 \mathrm{mM} \mathrm{NaCl}, 20 \mathrm{mM} \mathrm{HEPES}, \mathrm{pH} 8.0$ ) and subsequently lysed using French Press. The lysate was incubated at $70{ }^{\circ} \mathrm{C}$ for $10 \mathrm{~min}$ to reduce $E$. coli contaminants and the heat stable cell free lysate was collected using $18000 \mathrm{rpm}$ for $20 \mathrm{~min}$. The supernatant was loaded on $5 \mathrm{ml} \mathrm{Ni-NTA}$ column (Protino ${ }^{\mathrm{TM}}$ ) and washed with $6 \mathrm{CV}$ lysis buffer before eluting the protein with $4 \mathrm{CV}$ elution buffer (lysis buffer with $500 \mathrm{mM}$ imidazole). The elution was concentrated and further purified by size exclusion chromatography using a HiLoad ${ }^{\circledR} 26 / 600$ Superdex ${ }^{\circledR} 200$ PG (GE Healthcare) column equilibrated with SEC-buffer (200 mM NaCl, $50 \mathrm{mM}$ Tris, pH 9.0). SaTTM protein purity was monitored using a Coomassie stained $15 \%$ SDS-PAGE. The oligomerization of SaTTM was checked on an analytical Superdex ${ }^{\circledR} 20010 / 300$ GL column and using SEC buffer system. Pure protein was concentrated and stored at $-80^{\circ} \mathrm{C}$ until activity assays or crystallization.

\section{Crystallization of SaTTM}

To obtain SaTTM crystals $10 \mathrm{mg} / \mathrm{ml}$ protein in SEC-buffer was mixed with the respective precipitant in an equal volume ratio. Crystals were grown at $4^{\circ} \mathrm{C}$ using sitting-drop vapour diffusion. For the ATP state, $10 \mathrm{mM} \mathrm{CaCl}_{2}$ and $5 \mathrm{mM} \mathrm{ATP} \mathrm{were} \mathrm{added} \mathrm{to} \mathrm{the} \mathrm{protein} \mathrm{solution.}$ The best diffracting crystal appeared in condition JCSG Core IE7 (0.2 M Calcium acetate, $0.1 \mathrm{M}$ MES pH 6.0, 20\% (w/v) PEG 8000). The relaxed state of SaTTM (PDB: 7NS8) originated from the ATP screen in a precipitant condition with $0.2 \mathrm{M}$ Lithium sulphate, $0.1 \mathrm{M}$ CAPS $\mathrm{pH}$ 10.5, $2 \mathrm{M}$ ammonium sulphate. High concentration of sulphate in the precipitation condition competed out the phosphate substrate from the active site. The Michaelis complex was obtained from a SaTTM mixed with $10 \mathrm{mM} \mathrm{CaCl}$ (or $10 \mathrm{mM} \mathrm{MgCl}_{2}$ ), $0.5 \mathrm{mM} \mathrm{MgCl}_{2}$, and $5 \mathrm{mM}$ of hexa-polyphosphate, $\mathrm{P}_{6} \mathrm{i}$ (or tri-polyphosphate, PPPi). Both, $\mathrm{PPPi}+\mathrm{Ca}^{2+}$ and PPPi+ $\mathrm{Mg}^{2+}$, crystallized in $0.2 \mathrm{M} \mathrm{NaCl}, 0.1 \mathrm{M} \mathrm{Na} / \mathrm{KPO}_{4} \mathrm{pH} 6.2,20 \%$ (w/v) PEG 1000. Note, the hexa-polyphosphate was highly impure as detected by malachite green assay (data not shown). The product (PPi) inhibited SaTTM in presence of $10 \mathrm{mM} \mathrm{CaCl}_{2}$ and $5 \mathrm{mM} \mathrm{PPi}$ was crystallized in $0.17 \mathrm{M}$ ammonium acetate, $0.085 \mathrm{M}$ sodium acetate $\mathrm{pH} 4.6,25.5 \%(\mathrm{w} / \mathrm{v})$ PEG $4000,15 \%(\mathrm{v} / \mathrm{v})$ glycerol. Crystals were harvested at $4^{\circ} \mathrm{C}$ as temperature seems to have significant effect on crystallization of SaTTM complexes. Crystals were cryoprotected in mother liquor supplemented with $30 \%$ glycerol except the PPPi- $\mathrm{Mg}^{2+}$ complex and subsequently flash frozen using liquid nitrogen for data collection.

\section{Structure solution}

X-ray data for different states of SaTTM were collected from single crystals at the ESRF (Grenoble, France). Crystallography data were processed using iMOSFLM in the CCP4i2 package (37). Initial phases for SaTTM-ATP-Ca ${ }^{2+}$ were obtained using a SWISS-model (38) of SaTTM, based on PDB entry 2EEN (identity $42 \%$ ) as a search model for molecular replacement in Phaser-MR (39). Atomic models of the other crystallized states of SaTTM were obtained by using the structure of SaTTM in complex with ATP and calcium as a search model for Phaser-MR. Iterative model building and refinements was performed with COOT and Phenix.refine $(40,41)$. Data collection and refinement statistics are summarized in Table S2. The resulting coordinates were deposited at the protein data bank under accession numbers 
7NS8, 7NS9, 7NSA, 7NSF, and 7NSD. The structural analysis and figure generation was performed with UCSF Chimera (42).

\section{Activity assay}

Triphosphatase activity of SaTTM was analysed with the Malachite Green Phosphate Assay Kit (MAK307-1KT) from Sigma Aldrich according to manufacturer's protocol. Reactions were quenched by mixing $80 \mu$ assay mix into $20 \mu \mathrm{l}$ working reagent using 96 well PS F-bottom microplates (Greiner). After colour development for $30 \mathrm{~min}$ at room temperature, the absorbance was measured at $620 \mathrm{~nm}$ using a plate reader (photospectrometer Infinite 200, Tecan). The results were analysed with Microsoft Excel and GraphPad Prism. The pH optimum of SaTTM was determined by measuring the amount of reaction product (Pi release) from $5 \mathrm{nM}$ SaTTM, $2 \mathrm{mM} \mathrm{MgCl}$, and $0.1 \mathrm{mM}$ PPPi buffered in $50 \mathrm{mM}$ Tris and $200 \mathrm{mM} \mathrm{NaCl}$ at varying $\mathrm{pH}$ values (6.1-9.1) after $5 \mathrm{~min}$ incubation. To determine the preferred metal cofactor, $5 \mathrm{nM}$ SaTTM, $2 \mathrm{mM}$ metal ion $\left(\mathrm{Mg}^{2+}, \mathrm{Ca}^{2+}, \mathrm{Mn}^{2+} \mathrm{Zn}^{2+} \mathrm{Ni}^{2+}\right.$ and $0.1 \mathrm{mM}$ PPPi were incubated at $75^{\circ} \mathrm{C}$ for $5 \mathrm{~min}$ buffered in $50 \mathrm{mM}$ Tris and $200 \mathrm{mM} \mathrm{NaCl}$ at pH 8.6. The preferred substrate was analysed by using the same parameters for 10 min with $\mathrm{Mg}^{2+}$ as a cofactor and varying substrates (PPPi, ATP, GTP, AP4A, AP5A) at $0.1 \mathrm{mM}$ concentration. Mutant activities were determined accordingly with 5 min incubation. In order to test the product inhibition, as well as the ability of $\mathrm{Ca}^{2+}$ to inhibit SaTTM, a titration series of $1 \mathrm{nM}$ to $10 \mathrm{mM}$ inhibitor (PPi or $\mathrm{Ca}^{2+)}$ was performed by measuring their influence on the product formation of $5 \mathrm{nM}$ SaTTM, 2 $\mathrm{mM} \mathrm{MgCl} 2$, and $0.1 \mathrm{mM}$ PPPi buffered in $50 \mathrm{mM}$ Tris and $200 \mathrm{mM} \mathrm{NaCl}$ at pH 8.6 incubated for 5 and $10 \min$ at $75^{\circ} \mathrm{C}$.

To analyse the enzyme kinetics of SaTTM phosphatase activity, $5 \mathrm{nM}$ enzyme was incubated together with $2 \mathrm{mM} \mathrm{MgCl}_{2}$ and varying PPPi concentrations $(0.005$ to $0.5 \mathrm{mM})$ incubated in 50 $\mathrm{mM}$ Tris and $200 \mathrm{mM} \mathrm{NaCl}$ at $\mathrm{pH} 8.6$ and $75^{\circ} \mathrm{C}$. To obtain kinetic parameters, the velocities at different substrate concentrations were determined by measuring the $\mathrm{Pi}$ formation at different time points and the resulting linear regressions of four measurements were used for the Michaelis-Menten analysis.

To check products on HPLC, the reactions were diluted 5-fold with double-distilled water and the enzyme denatured by adding $100 \mu$ chloroform followed by $15 \mathrm{~s}$ of vigorous shaking, $15 \mathrm{~s}$ heat denaturation at $95^{\circ} \mathrm{C}$ and snap freezing in liquid nitrogen. The samples were thawed, the two phases separated by centrifugation $\left(17,300 \times \mathrm{g}, 10 \mathrm{~min}, 4^{\circ} \mathrm{C}\right)$ and $10 \mu \mathrm{l}$ of the aqueous phase containing the nucleotides subjected to HPLC analysis. Nucleotides were separated with an anion exchange column (Metrosep A Supp 5 - 150/4.0) with $100 \mathrm{mM}\left(\mathrm{NH}_{4}\right)_{2} \mathrm{CO}_{3} \mathrm{pH}$ 9.25 at a flow rate of $0.7 \mathrm{ml} / \mathrm{min}$ as eluent and detected at $260 \mathrm{~nm}$ wavelength in agreement with standards.

For the activity analysis of SaTTM towards $\mathrm{P}_{4}, 21 \mu \mathrm{M}$ SaTTM were incubated in a total volume of $150 \mu$ together with $15 \mathrm{mM}$ Tris $\mathrm{pH} 7.5$ and $4 \mathrm{mM} \mathrm{MgCl} 2$ for $3 \mathrm{~min}$ at $75^{\circ} \mathrm{C}$. The reaction was initiated by the addition of $0.5 \mathrm{mM} \mathrm{P}_{4}$ and terminated after 10 min through incubation on ice for $10 \mathrm{~min}$, followed by centrifugation in a spin filter to remove the enzyme $\left(4^{\circ} \mathrm{C}, 35 \mathrm{~min}\right.$, $10.0 \times 1000 \mathrm{rcf}$, Amicon-Ultra 0.5, $10 \mathrm{kDa}$ ). The flow through was analysed by ionic exchange chromatography using a Thermo Scientific Dionex ${ }^{\mathrm{TM}}$ ICS-5000+ equipped with a conductivity detector and an EGC500 eluent generator. $10 \mu \mathrm{l}$ of the flow through were injected followed by elution with a flow rate of $0.25 \mathrm{ml} / \mathrm{min}$ and a KOH gradient starting from $5 \mathrm{mM} \mathrm{KOH}$. The eluent was raised to $12 \mathrm{mM}$ within $5 \mathrm{~min}$, followed by an increase to $20 \mathrm{mM}$ until 10 min and $70 \mathrm{mM}$ within $15 \mathrm{~min}$. $\mathrm{KOH}$ concentration was maintained at $70 \mathrm{mM}$ until $26 \mathrm{~min}$, subsequently lowered to $5 \mathrm{mM}$ at $26.1 \mathrm{~min}$ followed by equilibration until termination of the run at $27 \mathrm{~min}$.

\section{Sequence similarity network}

The protein family PF01928 (CYTH) was used as input for the Enzyme Similarity Tool provided by the Enzyme Function Initiative (14) to generate the sequence-similarity network (SSN). Using the domain boundaries and an E-value of $10^{-5}$, the initial network was generated and subsequently modified by applying higher stringent cut offs $\left(10^{-15}, 10^{-20}\right)$ as alignment scores for the final SSNs. Each node represents proteins with $>40 \%$ identity. The resulting networks 
were subjected to the recently implemented cluster analysis for automatic cluster-WEBLOGO generation and the final networks were analysed with Cytoscape $3.5 .1(43,44)$.

\section{Data availability}

The atomic coordinates of the crystal structures of SaTTM, SaTTM/PPPi/Ca ${ }^{2+}$, SaTTM/PPi/Ca ${ }^{2+}$, SaTTM/PPPi/Mg ${ }^{2+}$, and SaTTM/ATP/Ca ${ }^{2+}$ have been deposited in the Protein Data Bank (PDB ID codes 7NS8, 7NS9, 7NSA, 7NSF, and 7NSD, respectively).

\section{Acknowledgments}

We thank Dr. Xing Ye for his guidance and advises and the group of Prof. Henning J. Jessen (Institute of Organic Chemistry, Albert-Ludwigs-Universität Freiburg) for substrate and IC system supply. We also thank Ralf Pöschke (MarXtal facility, Marburg) for technical support during crystallization and the staff of beamlines ID23-1, ID29, and ID30B at the European Synchrotron Radiation Facility (Grenoble, France) for support with data collection. Further, we thank Dr. Lena Hoffmann for cloning the initial SaTTM vector, Julian Grützner and Abbas Sajediabkenar for their help during their internships, and Dr. Wieland Steinchen for assistance with HPLC measurements.

\section{Author contributions}

MSV, RRN, MKFM and AB performed experiments. MSV, LOE and AB planned experiments, analyzed data, prepared initial draft, and finalized the manuscript draft. LOE and SVA revised the manuscript.

\section{Funding and additional information}

This work was supported by DFG grant SFB 987 (Collaborative Research Center 987) and Volkswagen Foundation (Az96727) to LOE, MSV and SVA. AB is supported by DFG fellowship (666472).

\section{Conflict of interest}

The authors declare no competing interest. 


\section{Figures}

Figure 1 Sequence similarity network of CYTH proteins. The CYTH family PF01928 is presented as a sequence-similarity network, generated with the EFI-EST using the domain boundaries and a final alignment score of $10^{-20}(14)$. Each node represents sequences with $>40 \%$ identity and the final network was subjected to the cluster analysis implemented by the EFI-EST. Accordingly, the ten largest clusters were subjected for further analysis, including all currently described CYTH enzymes (see Table S1). Known TTMs are found in clusters 13,5 , and 9. ThTPase enzymes appear exclusively in cluster 8 and CyaB/AC-IV's belong to cluster 10. Proteins from cluster 4 are unknown and cluster 7 members lack the hallmark motif ExExK. If available, PDB entries are given in parentheses. The network with $E<10^{-15}$ and WEBLOGOs of clusters 1-10 are shown in Figure S7+8.

Figure 2 The main substrate of SaTTM is PPPi and not nucleotides. A For substrate specificity, $5 \mathrm{nM}$ SaTTM were incubated with $2 \mathrm{mM} \mathrm{MgCl} 2$ and $0.1 \mathrm{mM}$ substrate at $\mathrm{pH} 8.6$ and $75^{\circ} \mathrm{C}$ for $10 \mathrm{~min}$. B The $\mathrm{pH}$ optimum of SaTTM peaks at $\mathrm{pH} 8.6$ within the tested range of 6.1 to 9.1 , using the conditions from A. C Different metal ions $\left(\mathrm{Mg}^{2+}, \mathrm{Zn}^{2+}, \mathrm{Mn}^{2+}, \mathrm{Ni}^{2+}\right.$, and $\mathrm{Ca}^{2+}$, EDTA as control, $2 \mathrm{mM}$ each) were examined to show their effect on SaTTM activity, using the conditions from $\mathbf{A}$ and an incubation time of $5 \mathrm{~min}$. D v/S diagram of SaTTM using $5 \mathrm{nM}$ enzyme, $0.005-0.5 \mathrm{mM}$ PPPi as substrate at $\mathrm{pH} 8.6$ and $75^{\circ} \mathrm{C}$. The kinetic parameters are noted.

Figure 3 The homodimer of SaTTM has an open and closed state. A The relaxed or open homodimer of SaTTM is shown as cartoon with the beta barrel being highlighted in orange and the rest being colored in petrol. The secondary structure elements are indicated on the right protomer. The cocrystallized sulfates and CAPS molecules (sticks with green carbons, red oxygens, and yellow sulfurs) are shown in one of the protomers for clarity, but are present in both, as the dimer has been generated by the symmetry mate due to just one molecule per $\mathrm{AU}$. $\mathrm{N}$ - and $\mathrm{C}$-termini of the protomers are indicated, the dashed lines indicate missing electron density for residues P44-R49 and Q73-R80. B The left panel shows the above orientation of the open states' surface as indicated by the arrow using the electrostatic coloring from negative (red) to positive (blue). The arrow indicates the closing movement upon ligand binding, resulting in the closed conformation shown on the right with the PPPi (orange and red sticks) substrate in orange bound within the tunnel. The dashed (open) circles indicate the conformation switch.

Figure 4 Catalytic states of SaTTM. A Residues (grey) in the binding tunnel of SaTTM are shown coordinating its substrate PPPi (orange sticks) and a magnesium ion (green sphere) at metal binding site 1. B Same orientation as in A of residues (grey) binding PPPi and two calcium ions (blue sphere) is shown. C For identification of triphosphate orientation, SaTTM is cocrystallized with ATP (yellow) and two calcium ions in the context of secondary structure elements (as indicated) and residues in purple. The superposition with the PPPi-calcium state from $B$ is shown with the indicated residues to assign the $\alpha$ - and $\gamma$-positions of the symmetric substrate in A, B, and D. D The product bound state of SaTTM in complex with PPi and calcium is shown with the same coloring scheme as in B. The PPPi is shown with contours only, identifying the $\alpha$ - and $\beta$-positions and further show that the three indicated waters (red spheres) localize at the $\gamma$-phosphate oxygen positions.

Figure 5 Different modes of substrate coordination among TTMs utilizing two conserved waters. A+B Superposition of substrate binding mode of CyaB (3NOZ, blue), AtTTM3 (5A5Y, green), and SaTTM (7NS8, brown) is shown in the context of secondary 
structure elements of SaTTM from two different angles as indicated. The magnesium cofactor (white sphere) from SaTTM is shown. Although mechanistically different, the binding modes of CyaB and SaTTM are highly similar regarding the establishment of the substrate waters, while AtTTM3 differs strikingly. B PPPi hydrolysis activities of the indicated residues show the impact of correct water placement by the DxY-motif and a positive effect on activity of a loosened plug helix.

Figure 6 Key motifs for substrate orientation and specificity of PF01928 enzymes. Superposition of the a. Adenylyl cyclase class IV enzymes possess an exclusive, N-terminal HF-motif for nucleobase stacking interaction by the phenylalanine. This motif is located four residues before the CYTH hallmark motif ExExK. The second motif identifies ThTPases using an aromatic residue to stack the organic part of the thiamine-triphosphate using the WxRxR motif. TTMs and AC-IV have small residue substitutes and the cyclases further exchanged the otherwise conserved centered arginine to a small, neutral residue, which is not sterically hindering correct ribose placement. The third, acidic ExE-motif is responsible for correct metal coordination. The first glutamate is conserved throughout the while family, as it is the central residue for metal 1 coordination, while the latter glutamate establishes the interaction to metal 2 , which is necessary for the catalytic mechanism in TTMs and ThTPases. This glutamate is strictly replaced by an alanine in the cyclase cluster 10 , suggesting the inability of metal 2 coordination. 


\section{Figure 1}

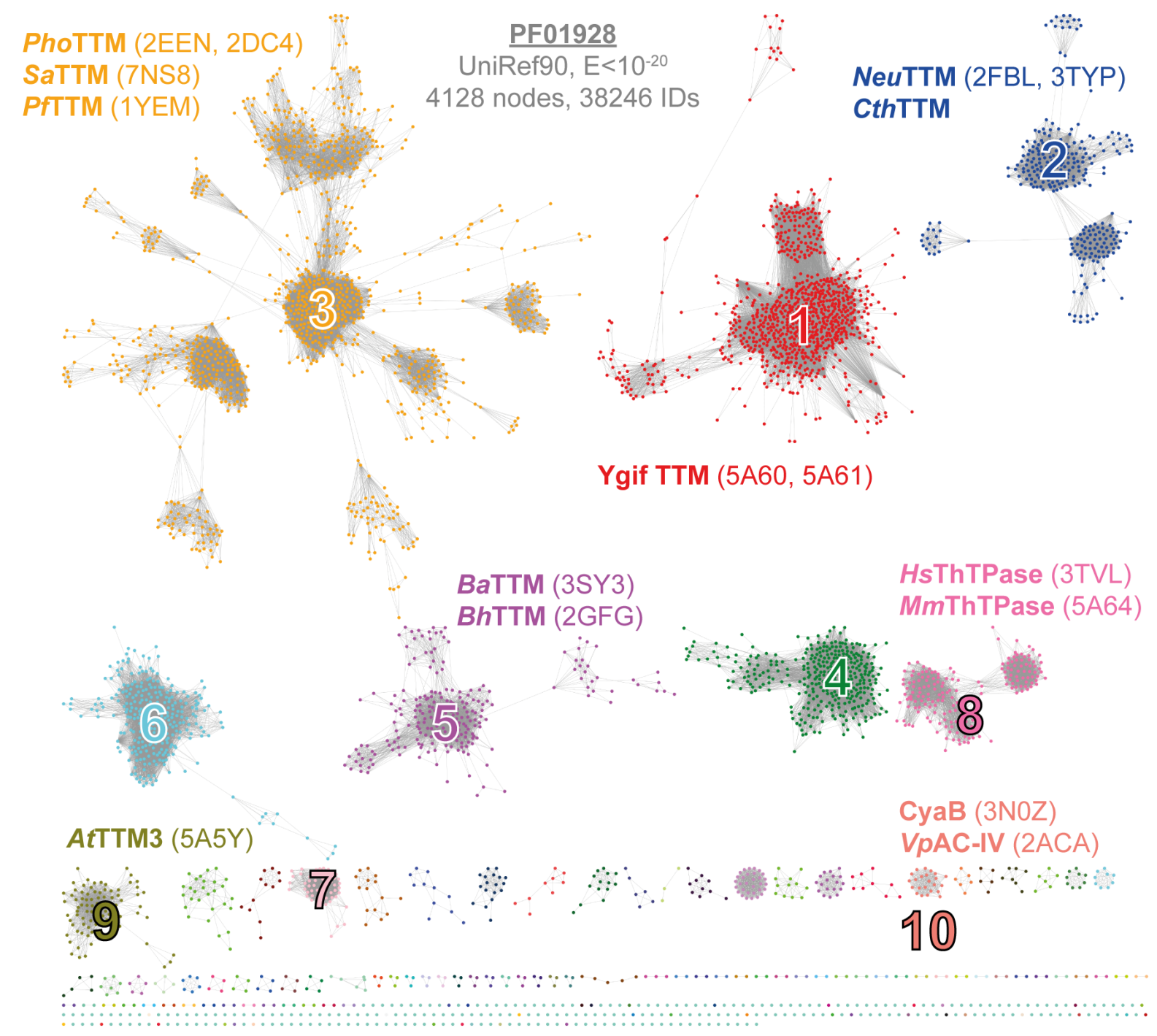


Figure 2
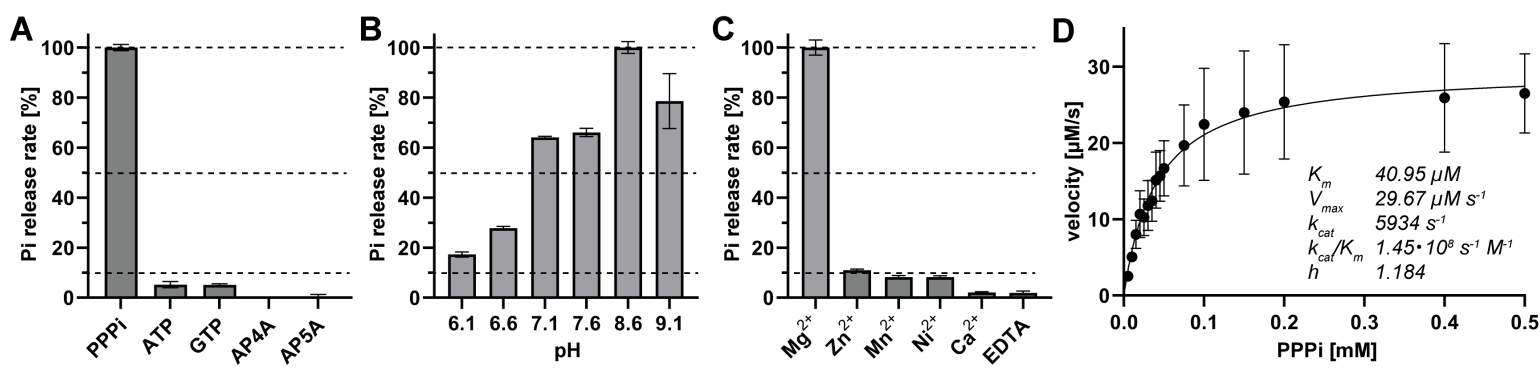


\section{Figure 3}

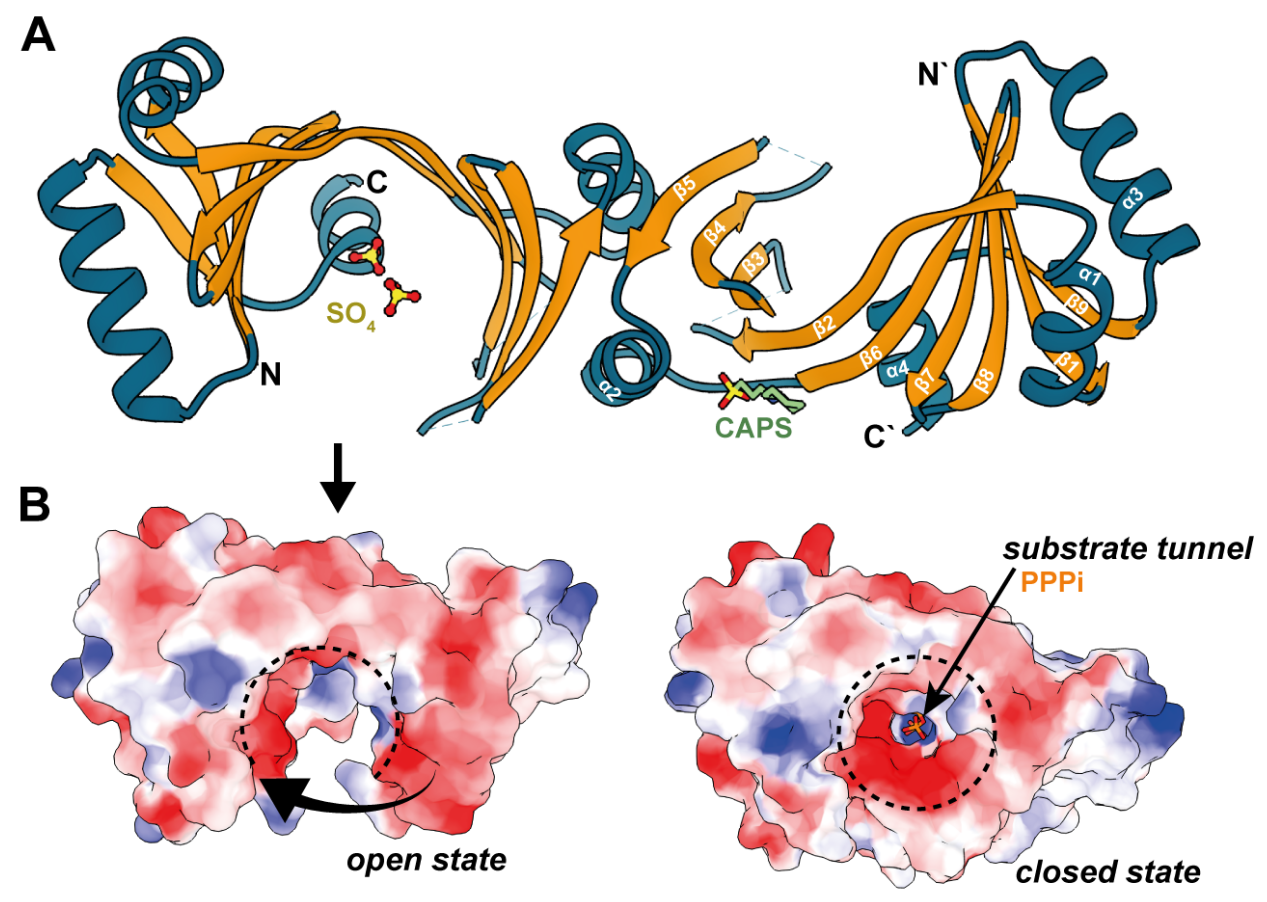




\section{Figure 4}
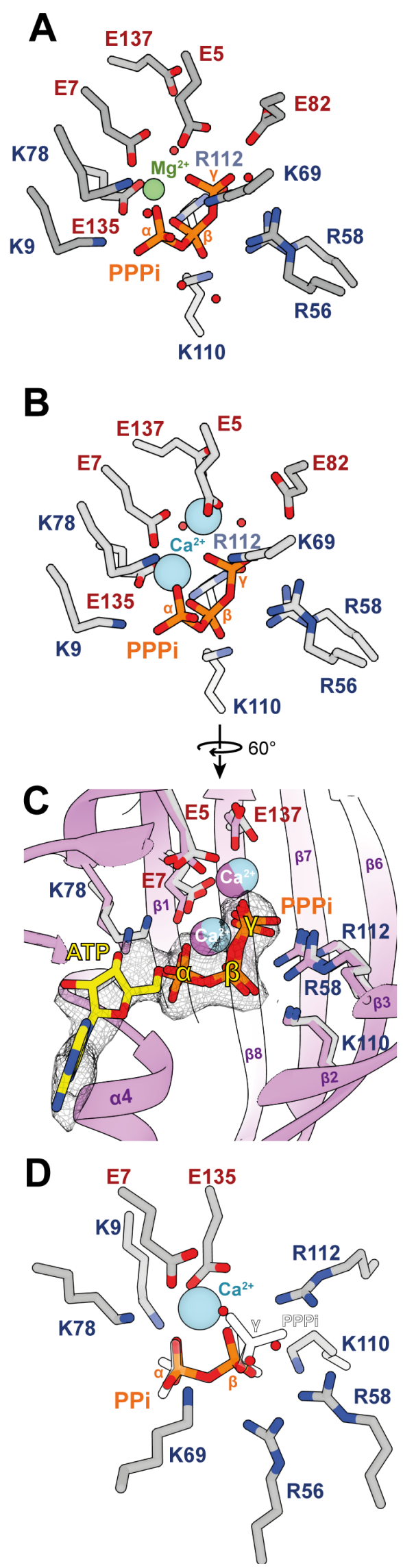


\section{Figure 5}
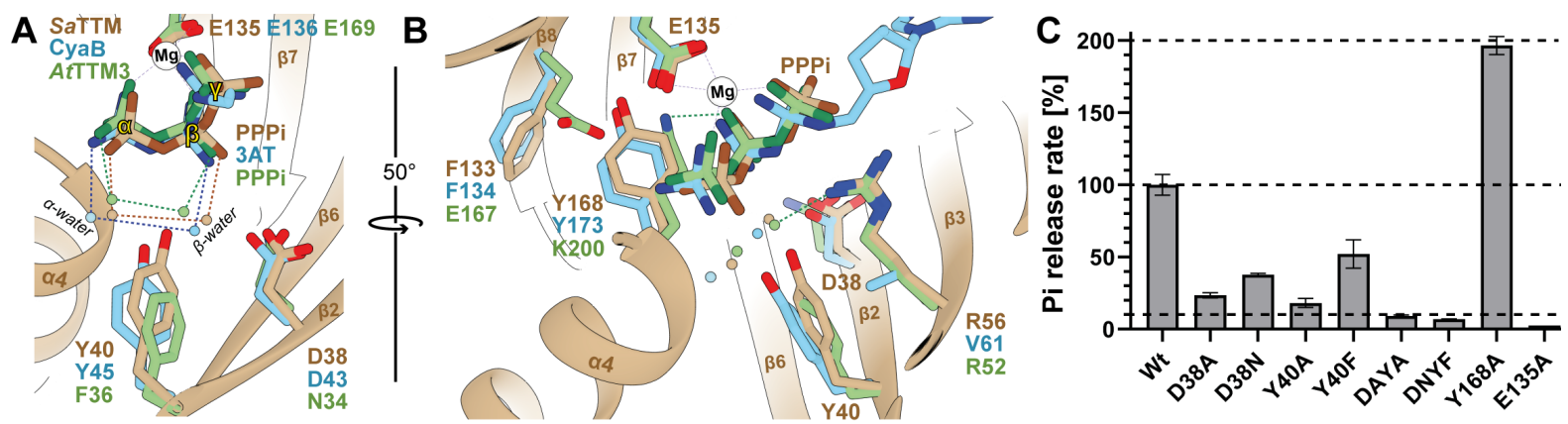
bioRxiv preprint doi: https://doi.org/10.1101/2021.03.18.435988; this version posted March 19, 2021. The copyright holder for this preprint (which was not certified by peer review) is the author/funder. All rights reserved. No reuse allowed without permission.

\section{Figure 6}

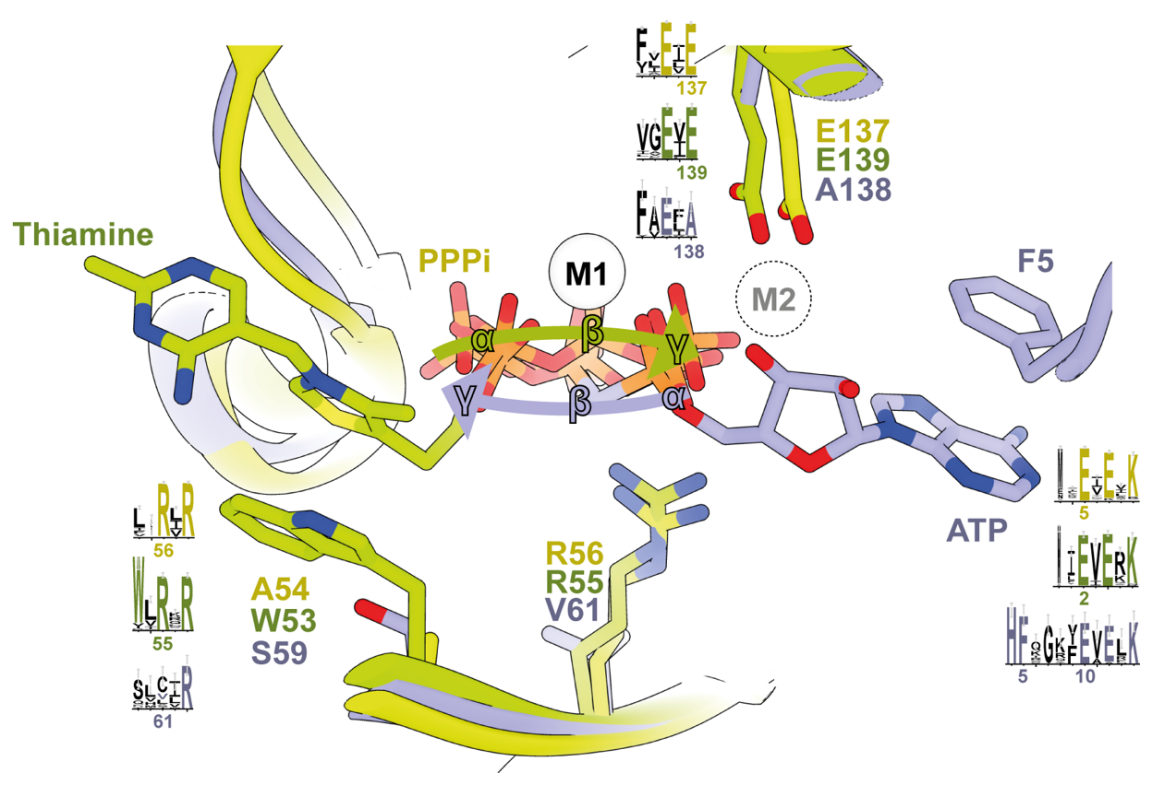




\section{References}

1. Iyer, L. M., and Aravind, L. (2002) The catalytic domains of thiamine triphosphatase and CyaB-like adenylyl cyclase define a novel superfamily of domains that bind organic phosphates. BMC Genomics. 3, 33

2. Keppetipola, N., Jain, R., and Shuman, S. (2007) Novel triphosphate phosphohydrolase activity of Clostridium thermocellum TTM, a member of the triphosphate tunnel metalloenzyme superfamily. J. Biol. Chem. 282, 11941-11949

3. Martinez, J., Truffault, V., and Hothorn, X. M. (2015) Structural determinants for substrate binding and catalysis in triphosphate tunnel metalloenzymes. J. Biol. Chem. 290, 23348-23360

4. Lima, C. D., Wang, L. K., and Shuman, S. (1999) Structure and mechanism of yeast RNA triphosphatase: An essential component of the mRNA capping apparatus. Cell. 99, 533-543

5. Gong, C., Smith, P., and Shuman, S. (2006) Structure-function analysis of Plasmodium RNA triphosphatase and description of a triphosphate tunnel metalloenzyme superfamily that includes Cet1-like RNA triphosphatases and CYTH proteins. Rna. 12, 1468-1474

6. Delvaux, D., Kerff, F., Murty, M. R. V. S., Lakaye, B., Czerniecki, J., Kohn, G., Wins, P., Herman, R., Gabelica, V., Heuze, F., Tordoir, X., Marée, R., Matagne, A., Charlier, P., De Pauw, E., and Bettendorff, L. (2013) Structural determinants of specificity and catalytic mechanism in mammalian 25-kDa thiamine triphosphatase. Biochim. Biophys. Acta - Gen. Subj. 1830, 4513-4523

7. Gallagher, D. T., Kim, S. K., Robinson, H., and Reddy, P. T. (2011) Active-site structure of class IV adenylyl cyclase and transphyletic mechanism. J. Mol. Biol. 405, 787-803

8. Steegborn, C. (2014) Structure, mechanism, and regulation of soluble adenylyl cyclases - similarities and differences to transmembrane adenylyl cyclases. Biochim. Biophys. Acta - Mol. Basis Dis. 1842, 2535-2547

9. Linder, J. U. (2006) Class III adenylyl cyclases: Molecular mechanisms of catalysis and regulation. Cell. Mol. Life Sci. 63, 1736-1751

10. Khannpnavar, B., Mehta, V., Qi, C., and Korkhov, V. (2020) Structure and function of adenylyl cyclases, key enzymes in cellular signaling. Curr. Opin. Struct. Biol. 63, 3441

11. Bettendorff, L., and Wins, P. (2013) Thiamine triphosphatase and the CYTH superfamily of proteins. FEBS J. 280, 6443-6455

12. Baumann, A., Lange, C., and Soppa, J. (2007) Transcriptome changes and cAMP oscillations in an archaeal cell cycle. BMC Cell Biol. 8, 1-19

13. Leichtling, B. H., Rickenberg, H. V., Seely, R. J., Fahrney, D. E., and Pace, N. R. (1986) The occurrence of cyclic AMP in archaebacteria. Biochem. Biophys. Res. Commun. 136, 1078-1082

14. Gerlt, J. A., Bouvier, J. T., Davidson, D. B., Imker, H. J., Sadkhin, B., Slater, D. R., and Whalen, K. L. (2015) Enzyme function initiative-enzyme similarity tool (EFI-EST): A web tool for generating protein sequence similarity networks. Biochim. Biophys. Acta - Proteins Proteomics. 1854, 1019-1037

15. Gallagher, D. T., Smith, N. N., Kim, S. K., Heroux, A., Robinson, H., and Reddy, P. T. (2006) Structure of the Class IV Adenylyl Cyclase Reveals a Novel Fold. J. Mol. Biol. $362,114-122$

16. Delvaux, D., Murty, M. R. V. S., Gabelica, V., Lakaye, B., Lunin, V. V., Skarina, T., Onopriyenko, O., Kohn, G., Wins, P., De Pauw, E., and Bettendorff, L. (2011) A specific inorganic triphosphatase from Nitrosomonas europaea: Structure and catalytic mechanism. J. Biol. Chem. 286, 34023-34035

17. Jain, R., and Shuman, S. (2008) Polyphosphatase activity of CthTTM, a bacterial triphosphate tunnel metalloenzyme. J. Biol. Chem. 283, 31047-31057

18. Ung, H., Karia, P., Ebine, K., Ueda, T., Yoshioka, K., and Moeder, W. (2017) Triphosphate tunnel metalloenzyme function in senescence highlights a biological 
diversification of this protein superfamily. Plant Physiol. 175, 473-485

19. Zhang, Y., Agrebi, R., Bellows, L. E., Collet, J. F., Kaever, V., and Gründling, A. (2017) Evolutionary adaptation of the essential tRNA methyltransferase TrmD to the signaling molecule 3',5'-cAMP in bacteria. J. Biol. Chem. 292, 313-327

20. Krissinel, E., and Henrick, K. (2007) Inference of Macromolecular Assemblies from Crystalline State. J. Mol. Biol. 372, 774-797

21. Sismeiro, O., Trotot, P., Biville, F., Vivares, C., and Danchin, A. (1998) Aeromonas hydrophila adenylyl cyclase 2: A new class of adenylyl cyclases with thermophilic properties and sequence similarities to proteins from hyperthermophilic archaebacteria, 10.1128/jb.180.13.3339-3344.1998

22. Moeder, W., Garcia-Petit, C., Ung, H., Fucile, G., Samuel, M. A., Christendat, D., and Yoshioka, K. (2013) Crystal structure and biochemical analyses reveal that the Arabidopsis triphosphate tunnel metalloenzyme AtTTM3 is a tripolyphosphatase involved in root development. Plant J. 76, 615-626

23. Świeżawska, B., Duszyn, M., Kwiatkowski, M., Jaworski, K., Pawełek, A., and SzmidtJaworska, A. (2020) Brachypodium distachyon triphosphate tunnel metalloenzyme 3 is both a triphosphatase and an adenylyl cyclase upregulated by mechanical wounding. FEBS Lett. 594, 1101-1111

24. Świezawska, B., Jaworski, K., Pawełek, A., Grzegorzewska, W., Szewczuk, P., and Szmidt-Jaworska, A. (2014) Molecular cloning and characterization of a novel adenylyl cyclase gene, HpAC1, involved in stress signaling in Hippeastrum $\mathrm{x}$ hybridum. Plant Physiol. Biochem. 80, 41-52

25. Ung, H., Moeder, W., and Yoshioka, K. (2014) Arabidopsis triphosphate tunnel metalloenzyme2 is a negative regulator of the salicylic acid-mediated feedback amplification loop for defense responses. Plant Physiol. 166, 1009-1021

26. Brown, M. R. W., and Kornberg, A. (2004) Inorganic polyphosphate in the origin and survival of species, 10.1073/pnas.0406909101

27. Rashid, M. H., and Kornberg, A. (2000) Inorganic polyphosphate is needed for swimming, swarming, and twitching motilities of Pseudomonas aeruginosa, 10.1073/pnas.060030097

28. Toso, D. B., Henstra, A. M., Gunsalus, R. P., and Zhou, Z. H. (2011) Structural, mass and elemental analyses of storage granules in methanogenic archaeal cells. Environ. Microbiol. 13, 2587-2599

29. Toso, D. B., Javed, M. M., Czornyj, E., Gunsalus, R. P., and Zhou, Z. H. (2016) Discovery and Characterization of Iron Sulfide and Polyphosphate Bodies Coexisting in Archaeoglobus fulgidus Cells. Archaea. 10.1155/2016/4706532

30. Scherer, P. A., and Bochem, H. P. (1983) Ultrastructural investigation of 12 Methanosarcinae and related species grown on methanol for occurrence of polyphosphatelike inclusions. Can. J. Microbiol. 29, 1190-1199

31. Remonsellez, F., Orell, A., and Jerez, C. A. (2006) Copper tolerance of the thermoacidophilic archaeon Sulfolobus metallicus: Possible role of polyphosphate metabolism. Microbiology. 152, 59-66

32. Li, L., Li, Q., Rohlin, L., Kim, U. M., Salmon, K., Rejtar, T., Gunsalus, R. P., Karger, B. L., and Ferry, J. G. (2007) Quantitative proteomic and microarray analysis of the archaeon Methanosarcina acetivorans grown with acetate versus methanol. J. Proteome Res. 6, 759-771

33. Paula, F. S., Chin, J. P., Schnürer, A., Müller, B., Manesiotis, P., Waters, N., Macintosh, K. A., Quinn, J. P., Connolly, J., Abram, F., McGrath, J. W., and O'Flaherty, V. (2019) The potential for polyphosphate metabolism in Archaea and anaerobic polyphosphate formation in Methanosarcina mazei. Sci. Rep. 9, 17101

34. Orell, A., Navarro, C. A., Rivero, M., Aguilar, J. S., and Jerez, C. A. (2012) Inorganic polyphosphates in extremophiles and their possible functions. Extremophiles. 16, 573-583

35. Recalde, A., van Wolferen, M., Sivabalasarma, S., Albers, S.-V., Navarro, C. A., and Jerez, C. A. (2021) The Role of Polyphosphate in Motility, Adhesion, and Biofilm 
Formation in Sulfolobales. Microorganisms. 9, 193

36. Albers, S. V., Szabó, Z., and Driessen, A. J. M. (2003) Archaeal homolog of bacterial type IV prepilin signal peptidases with broad substrate specificity. in Journal of Bacteriology, pp. 3918-3925, 185, 3918-3925

37. Potterton, L., Agirre, J., Ballard, C., Cowtan, K., Dodson, E., Evans, P. R., Jenkins, H. T., Keegan, R., Krissinel, E., Stevenson, K., Lebedev, A., McNicholas, S. J., Nicholls, R. A., Noble, M., Pannu, N. S., Roth, C., Sheldrick, G., Skubak, P., Turkenburg, J., Uski, V., Von Delft, F., Waterman, D., Wilson, K., Winn, M., and Wojdyr, M. (2018) CCP 4 i 2: The new graphical user interface to the CCP 4 program suite. Acta Crystallogr. Sect. D Struct. Biol. 74, 68-84

38. Waterhouse, A., Bertoni, M., Bienert, S., Studer, G., Tauriello, G., Gumienny, R., Heer, F. T., De Beer, T. A. P., Rempfer, C., Bordoli, L., Lepore, R., and Schwede, T. (2018) SWISS-MODEL: Homology modelling of protein structures and complexes. Nucleic Acids Res. 46, W296-W303

39. McCoy, A. J., Grosse-Kunstleve, R. W., Adams, P. D., Winn, M. D., Storoni, L. C., and Read, R. J. (2007) Phaser crystallographic software. J. Appl. Crystallogr. 40, 658-674

40. Afonine, P. V., Grosse-Kunstleve, R. W., Echols, N., Headd, J. J., Moriarty, N. W., Mustyakimov, M., Terwilliger, T. C., Urzhumtsev, A., Zwart, P. H., and Adams, P. D. (2012) Towards automated crystallographic structure refinement with phenix.refine. Acta Crystallogr. Sect. D Biol. Crystallogr. 68, 352-367

41. Emsley, P., Lohkamp, B., Scott, W. G., and Cowtan, K. (2010) Features and development of Coot. Acta Crystallogr. Sect. D Biol. Crystallogr. 66, 486-501

42. Pettersen, E. F., Goddard, T. D., Huang, C. C., Couch, G. S., Greenblatt, D. M., Meng, E. C., and Ferrin, T. E. (2004) UCSF Chimera - A visualization system for exploratory research and analysis. J. Comput. Chem. 25, 1605-1612

43. Cline, M. S., Smoot, M., Cerami, E., Kuchinsky, A., Landys, N., Workman, C., Christmas, R., Avila-Campilo, I., Creech, M., Gross, B., Hanspers, K., Isserlin, R., Kelley, R., Killcoyne, S., Lotia, S., Maere, S., Morris, J., Ono, K., Pavlovic, V., Pico, A. R., Vailaya, A., Wang, P. L., Adler, A., Conklin, B. R., Hood, L., Kuiper, M., Sander, C., Schmulevich, I., Schwikowski, B., Warner, G. J., Ideker, T., and Bader, G. D. (2007) Integration of biological networks and gene expression data using cytoscape. Nat. Protoc. 2, 2366-2382

44. Crooks, G. E., Hon, G., Chandonia, J. M., and Brenner, S. E. (2004) WebLogo: A sequence logo generator. Genome Res. 14, 1188-1190 


\section{Supplementary to "The archaeal triphosphate tunnel metalloenzyme SaTTM defines structural determinants for the diverse activities in the CYTH protein family"}

Marian S. Vogt ${ }^{1}$, Roi R. Ngouoko ${ }^{1}$, Michael K. F. Mohr ${ }^{2}$, Sonja-Verena Albers ${ }^{3}$, Lars-Oliver Essen $^{1,4 *}$, and Ankan Banerjee ${ }^{1,5 *}$

${ }^{1}$ Department of Chemistry, Philipps-Universität Marburg, Hans-Meerwein-Str. 4, D-35032 Marburg, Germany.

${ }^{2}$ Institute of Pharmaceutical Sciences, Albert-Ludwigs-Universität Freiburg, Albertstr. 25, D79104 Freiburg, Germany

${ }^{3}$ Institute of Biology II, Molecular Biology of Archaea, Albert-Ludwigs-Universität Freiburg, Schänzlestrasse 1, D-79104 Freiburg, Germany.

${ }^{4}$ Center for Synthetic Microbiology, Philipps-Universität Marburg, Hans-Meerwein-Str. 4 D35032 Marburg

${ }^{5}$ Department of Genetics, Philipps-Universität Marburg, Karl-Von-Frisch-Str 10, D-35043 Marburg, Germany.

${ }^{*}$ Corresponding author: Ankan Banerjee (banerjee@staff.uni-marburg.de) and Lars-Oliver Essen (essen@chemie.uni-marburg.de) 


\section{Supplementary figures}

\section{Figure S1}

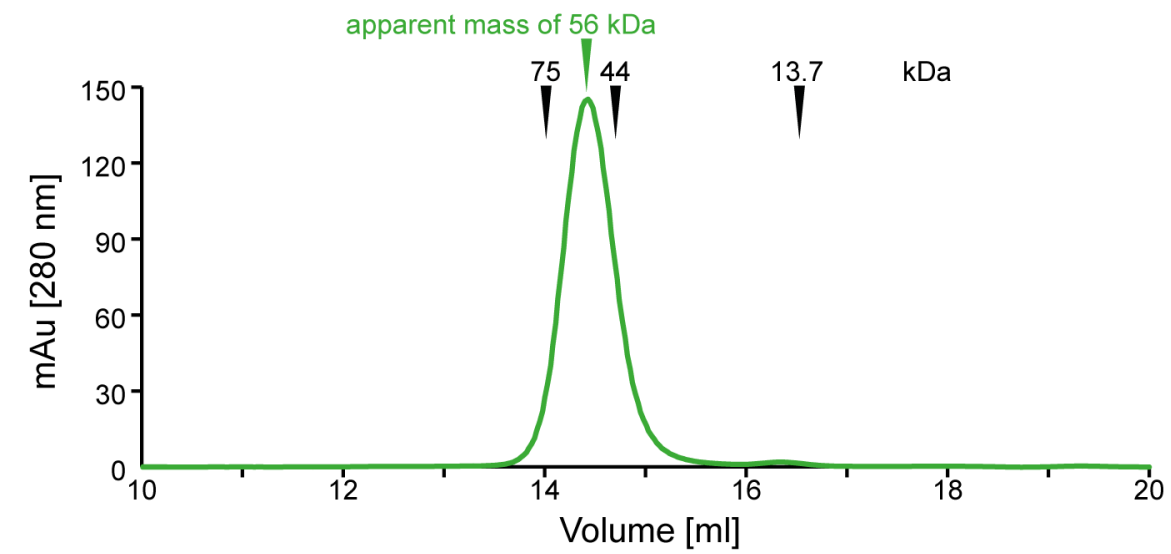

Figure S1 Calibrated SEC run of SaTTM on Biorad SEC650 column. Conalbumin (75 kDa), ovalbumin (44 kDa), and ribonuclease $A(13.7 \mathrm{kDa})$ were used as mass standards. The calculated molecular mass of the SaTTM monomer is $23.65 \mathrm{kDa}$, its SEC elution corresponds to a dimer in solution. 


\section{Figure S2}
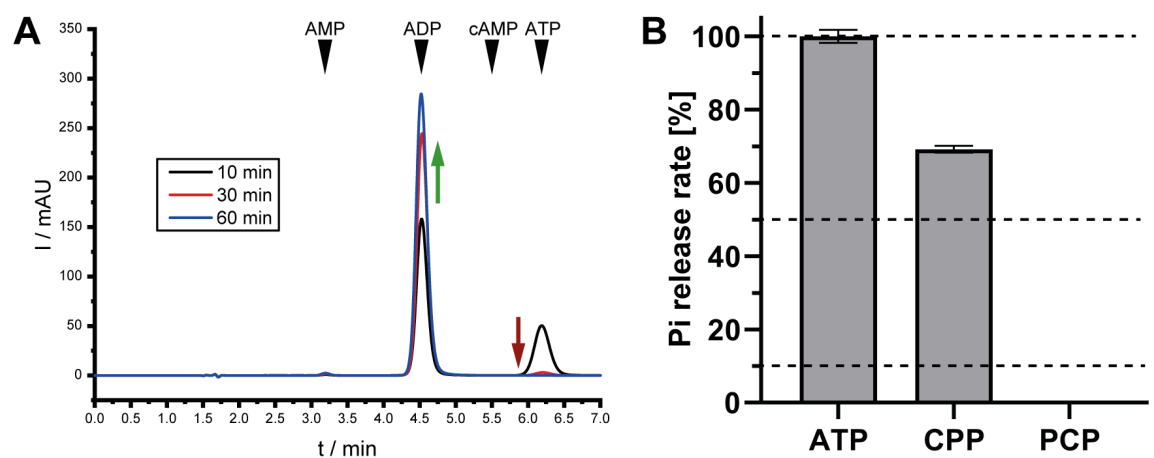

Figure S2 SaTTM converts ATP to ADP by releasing Y-phosphate. A Chromatograms of the time course of SaTTM hydrolyzing ATP to ADP is shown. As indicated by standards, no cAMP is produced. Arrows indicate the decrease (red) of substrate increase (green) of product over time. B SaTTM can utilize ATP and the non-hydrolysable ATP analog AMPCPP, but not AMPPCP, as a substrate. 


\section{Figure S3}

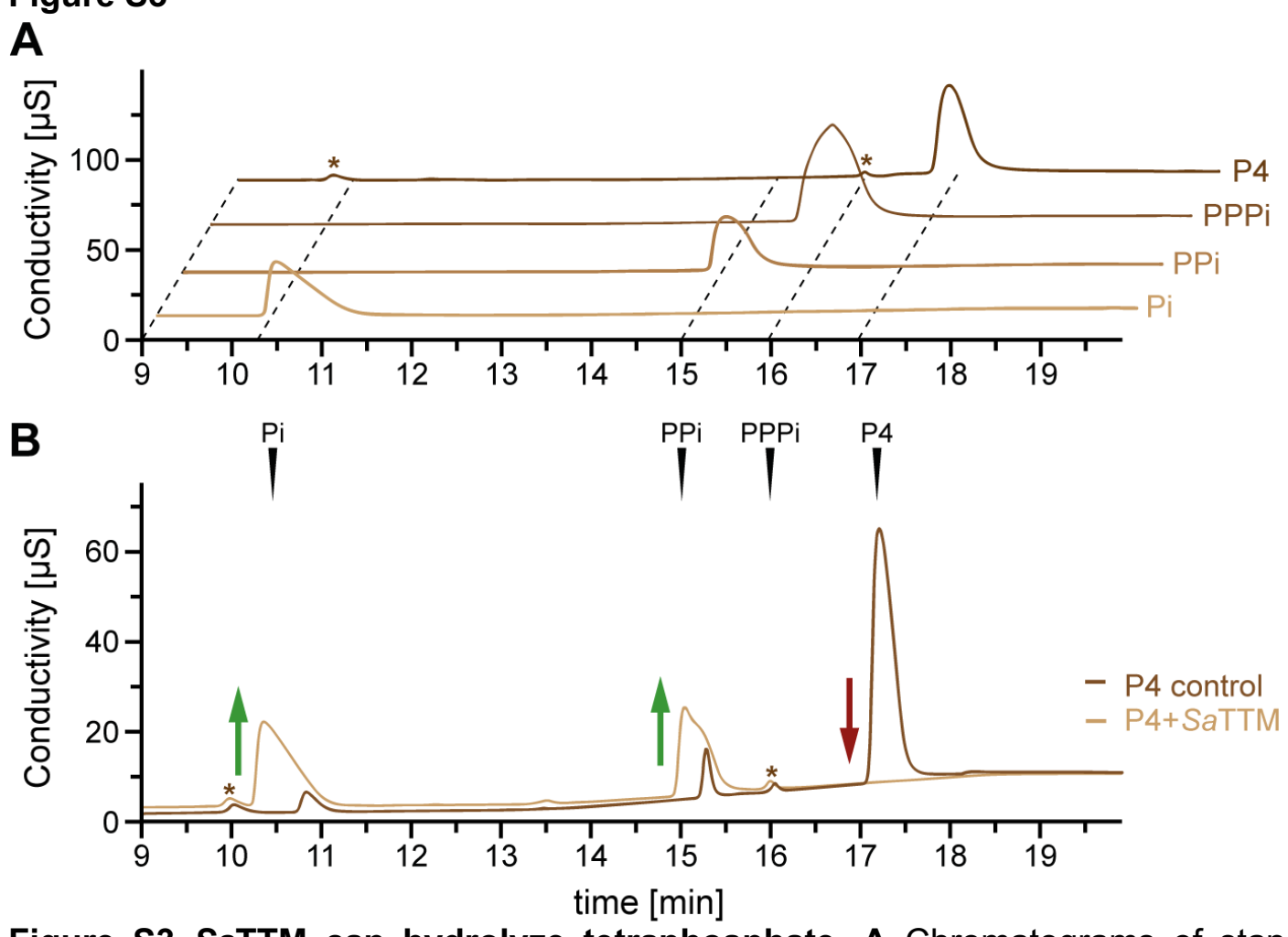

Figure S3 SaTTM can hydrolyze tetraphosphate. A Chromatograms of standards are shown for phosphate $(\mathrm{Pi})$, pyrophosphate (PPi), triphosphate (PPPi), and tetraphosphate (P4). B Chromatograms of P4 after incubation alone (brown) and together with SaTTM (ocher) show a complete turnover of $\mathrm{P} 4$ as indicated by the red arrow, while the products $\mathrm{Pi}$ and $\mathrm{PPi}$ increase (green arrows). The two unidentified peaks indicated by asterisks appear throughout the ion exchange chromatography run of P4 without being affected by the sample. 


\section{Figure S4}
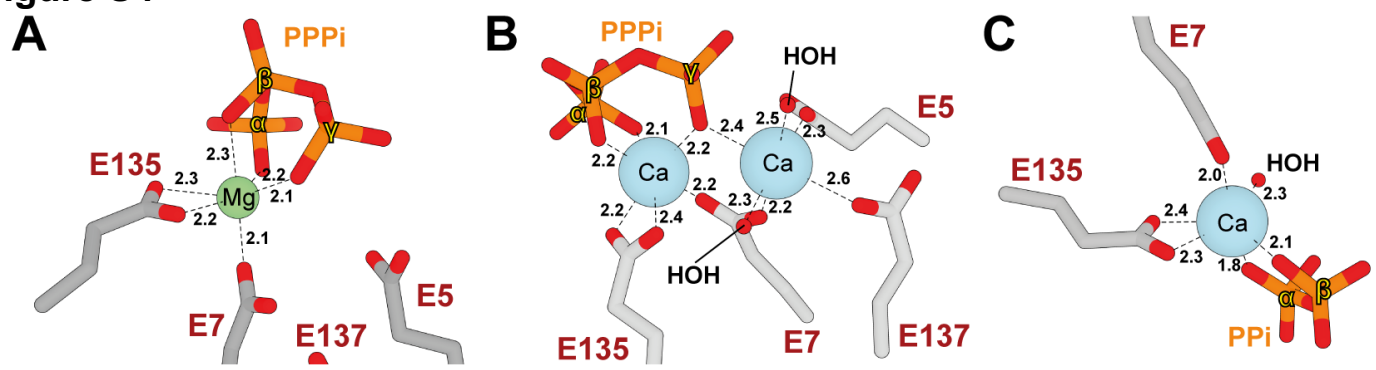

Figure S4 Distorted pseudo-octahedral metal ion coordination in SaTTM. The metal coordination of SaTTM PPPi $\bullet \mathrm{Mg}^{2+}(\mathbf{A}), \mathrm{PPPi} \mathrm{Ca}^{2+}(\mathbf{B})$, and PPi॰Ca${ }^{2+}(\mathbf{C})$ is shown indicated by the dashed lines and the respective distances shown in Angstrom. $\alpha-, \beta-$, and $\gamma$-positions of phosphates are indicated, so are the residues shown as grey sticks. Oxygens are colored in red, phosphorus in orange, magnesium as a green sphere and calcium as blue sphere. Waters are red spheres as indicated. 
Figure S5
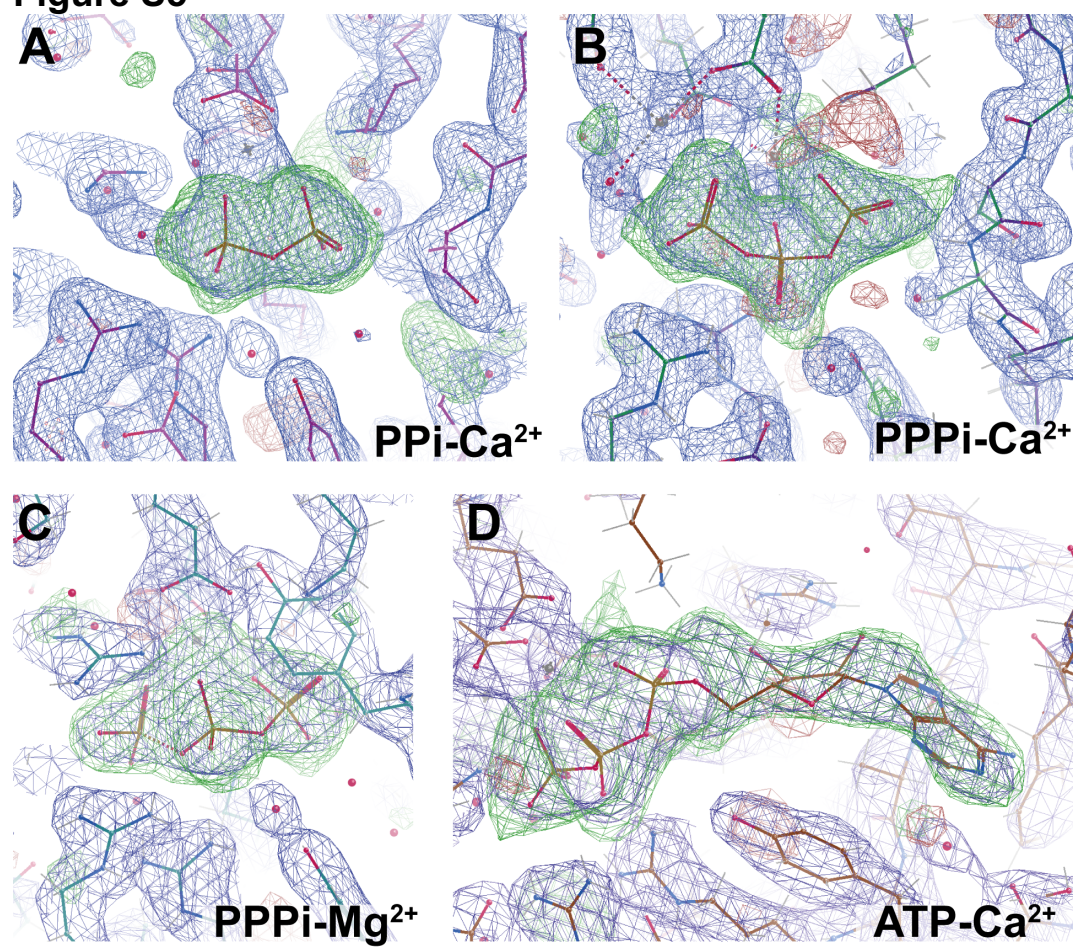

Figure S5 OMIT maps for the different catalytic states of SaTTM. OMIT maps of the respective ligands contoured at $\sigma$-level 3.0 are shown in the context of SIGMAA-weighted $2 \mathrm{mFo}$-DFC maps (blue mesh, contouring level: 1.5) of nearby residues. 
Figure S6

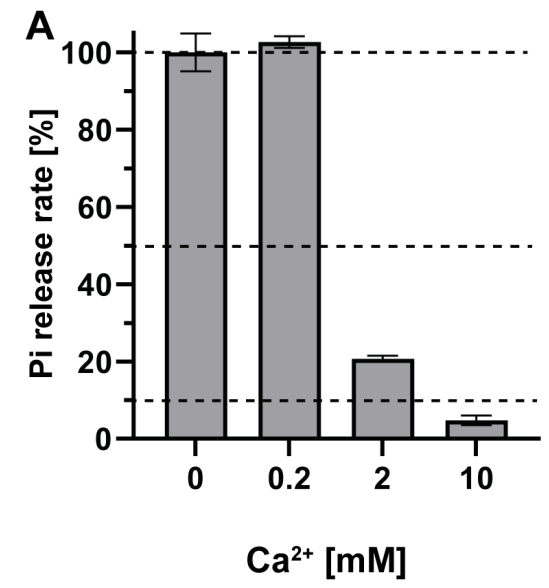

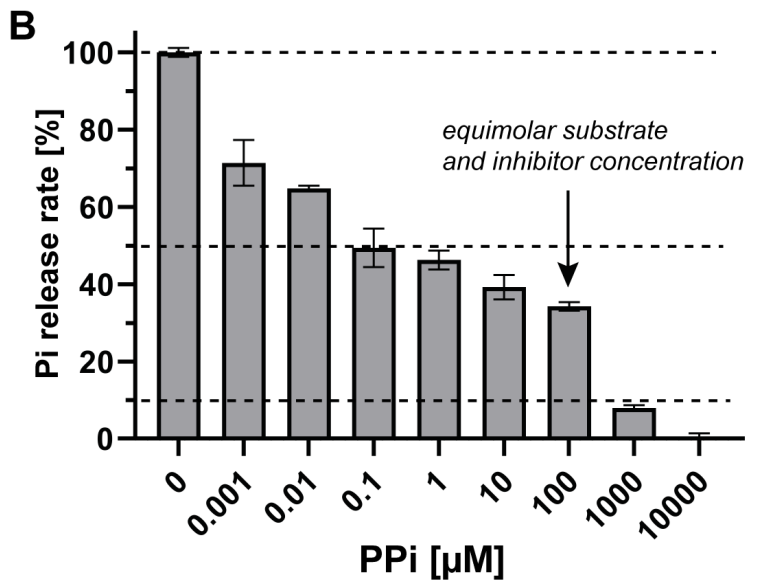

Figure S6 Titrations with inhibitory calcium and the product PPi. A The inhibiting effect of calcium on the triphosphatase activity of SaTTM is shown. B The presence of the product PPi has an inhibitory effect on the reaction behavior of SaTTM. 
Figure S7

A DOMAINS

$1 \mathrm{~N}-\mathrm{CYTH}$

$2 \mathrm{~N}$ CYTH $-\mathrm{C}$

$3 \mathbf{N}-$ CYTH $-\mathbf{C}$

$\Delta \mathrm{N}-\mathrm{CYTH}-\mathrm{C}$

$5 \mathrm{~N}-\mathrm{CYTH}-\mathrm{C}$

(อ) $\mathbf{N}-\mathrm{CYTH}-\mathrm{C}$

7

(8) $\mathrm{N}-\mathrm{CYTH}-\mathrm{C}$

(9) $\mathrm{N}-\mathrm{CYTH}-\mathrm{C}$

10) $\mathbf{N}-\mathrm{CYTH}-\mathrm{C}$

B

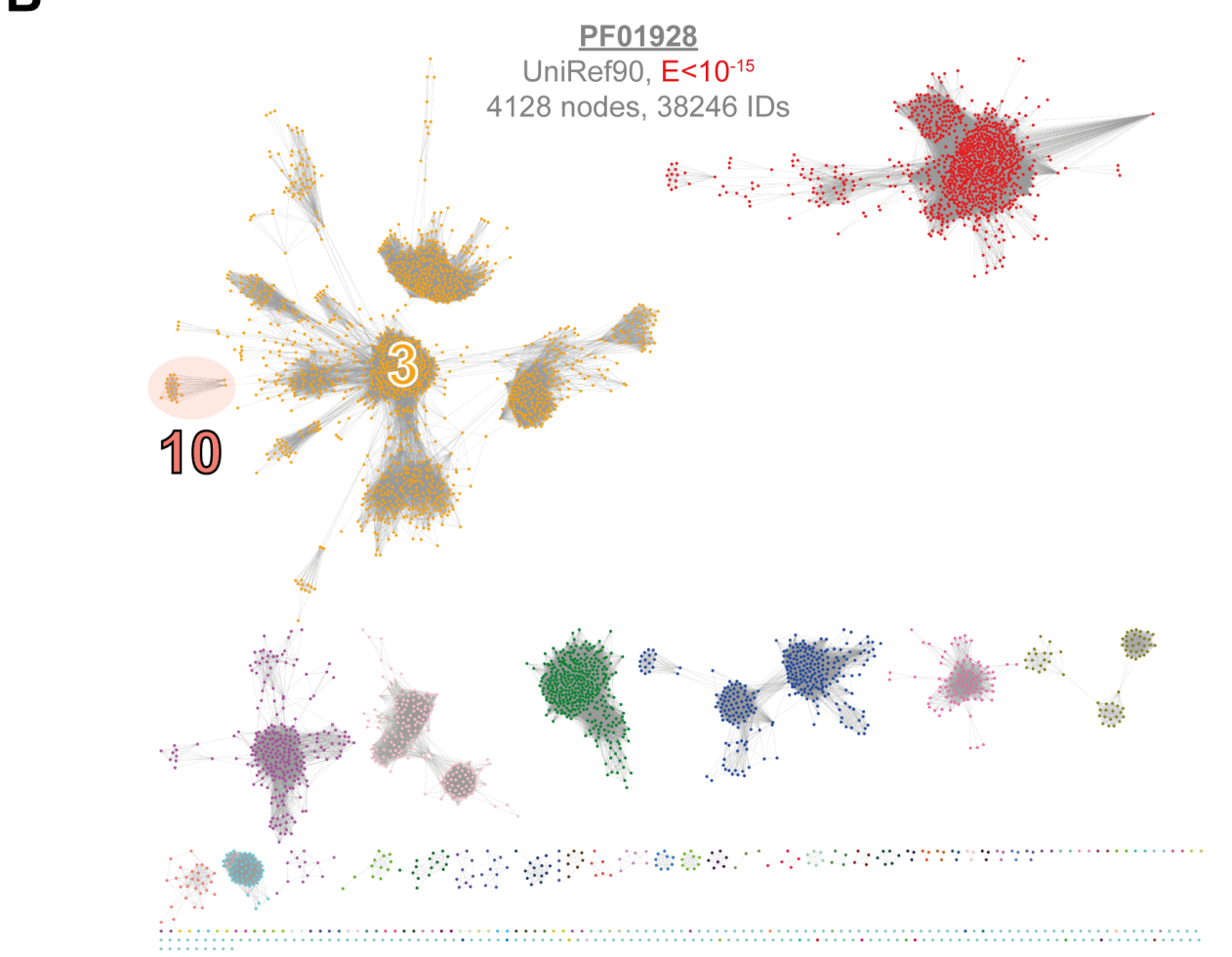

\section{MEMBERS}

Bacteria, Archaea

Bacteria, Archaea

Bacteria, Archaea

Bacteria,

Bacteria,

Bacteria, Archaea, Eukaryota

Eukaryota

Eukaryota

Eukaryota

Bacteria

Bacteria,
CYTH = PF01928

CHAD = PF05235

PRK = PF00485

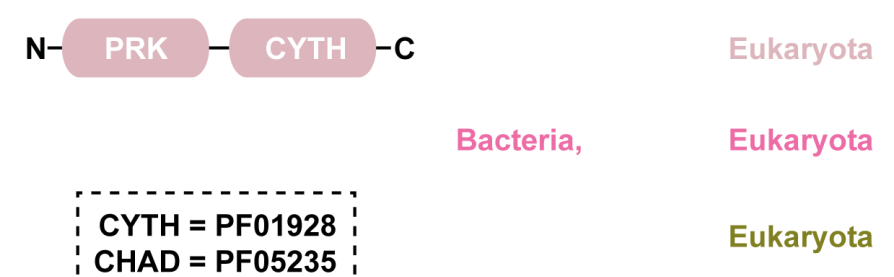

Bacterla

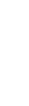

Figure S7 Domain architectures of PF01928 family and its SSN with lower stringency. A The prominent domain architectures present in the ten described clusters of the PF01928 family are shown with their appearance among the three kingdoms. The Pfam IDs are noted in the dashed box. B The PF01928 SSN with an alignment score of $E<10^{-15}$ is presented. 
bioRxiv preprint doi: https://doi.org/10.1101/2021.03.18.435988; this version posted March 19, 2021. The copyright holder for this preprint (which was not certified by peer review) is the author/funder. All rights reserved. No reuse allowed without permission.

Cluster 10 from the SSN in Fig. 1 is now member of cluster 3 (highlighted in transparent red). 
Figure S8 WEBLOGOS of PF01928 clusters 1-10.

WEBLOGO Cluster 1 comprising 868 entries from 2892 IDs within the SSN
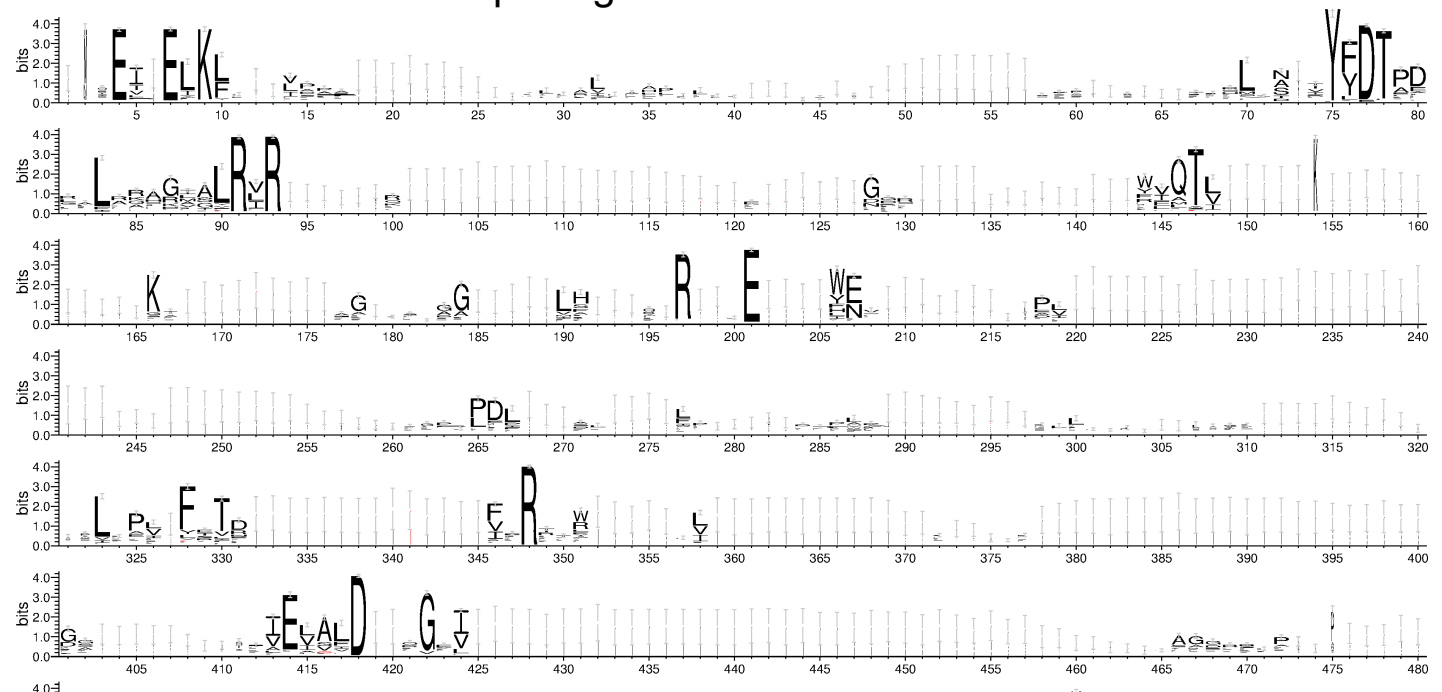

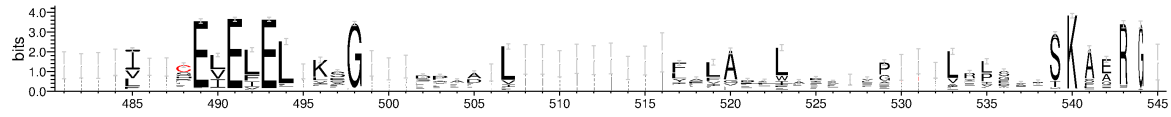

WEBLOGO Cluster 2 comprising 297 entries from 3199 IDs within the SSN
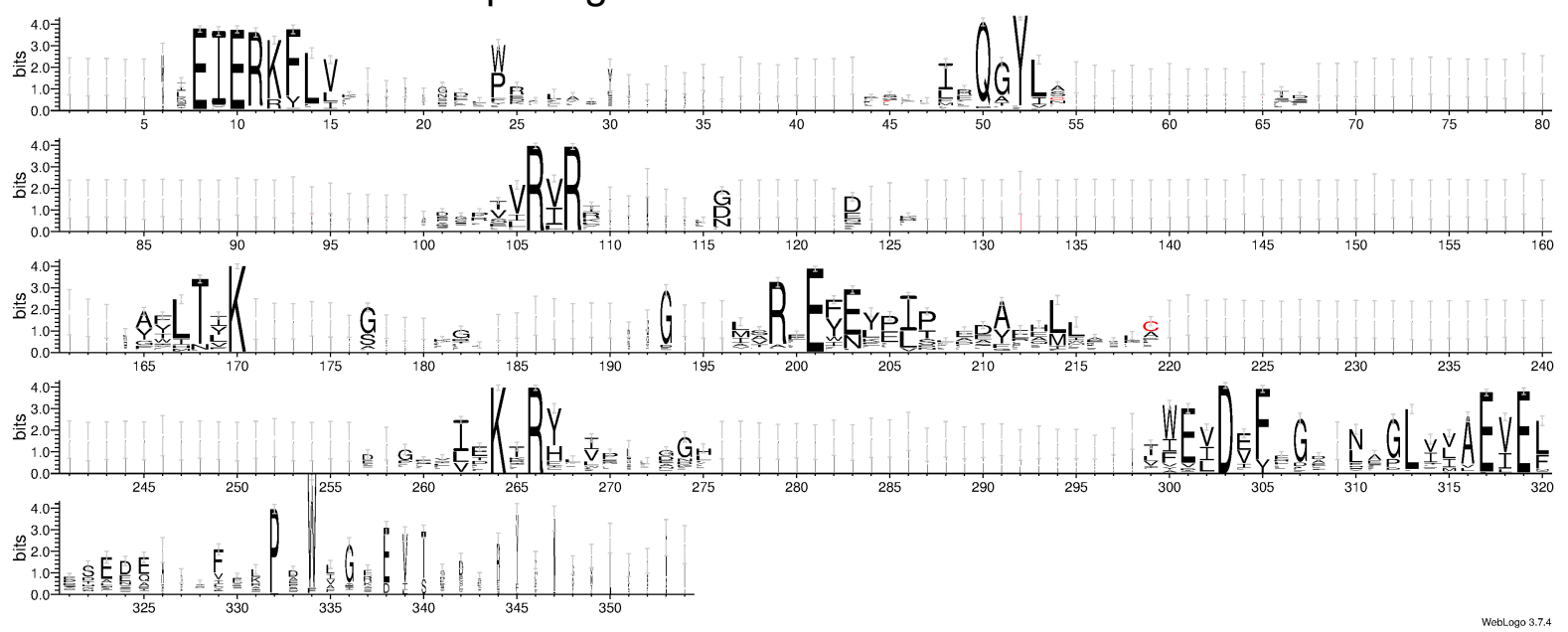
WEBLOGO Cluster 3 comprising 1062 entries from 2430 IDs within the SSN
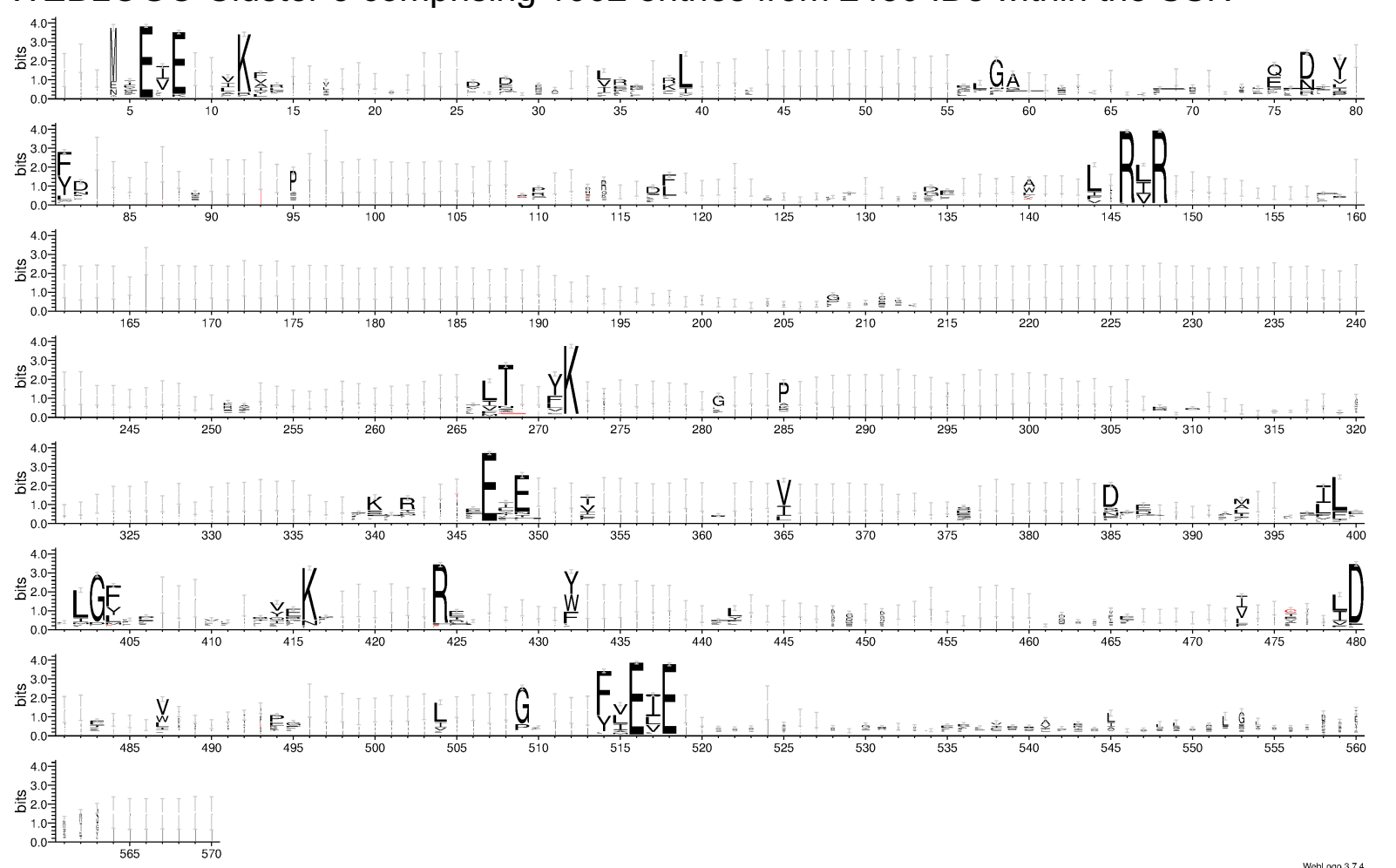

WEBLOGO Cluster 4 comprising 355 entries from 1644 IDs within the SSN
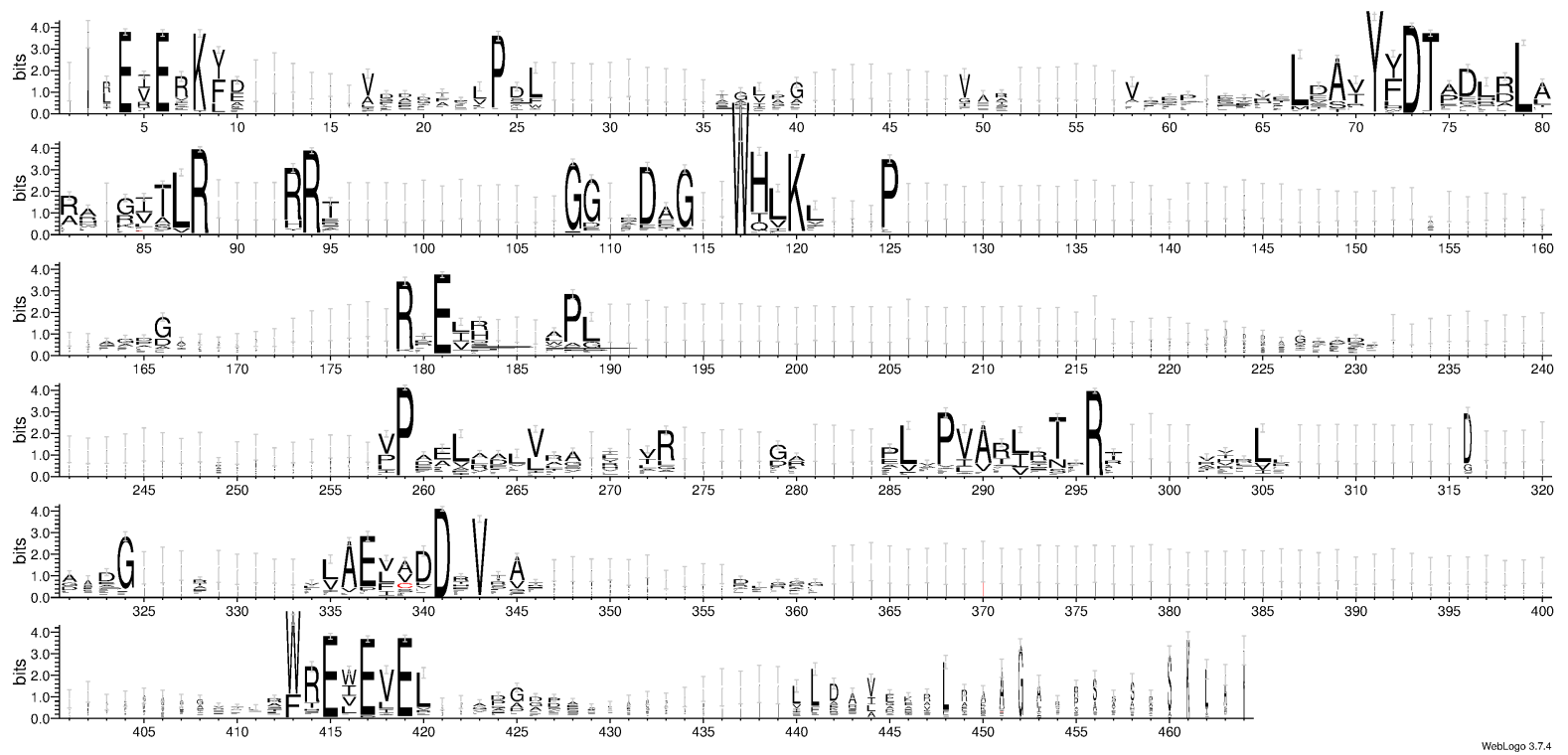
WEBLOGO Cluster 5 comprising 229 entries from 1001 IDs within the SSN

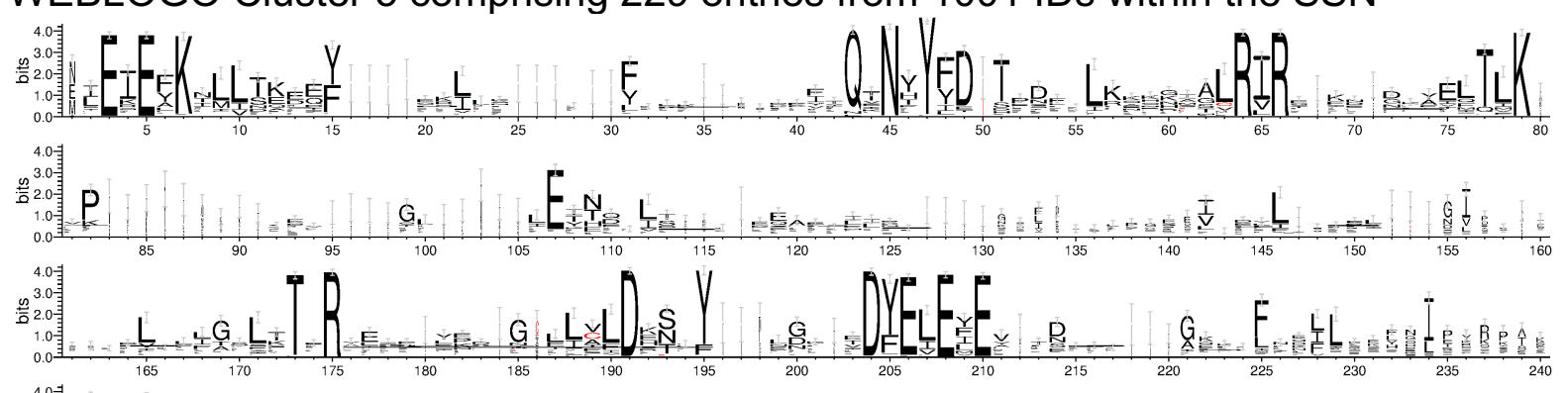

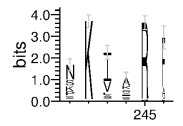

WEBLOGO Cluster 6 comprising 287 entries from 904 IDs within the SSN
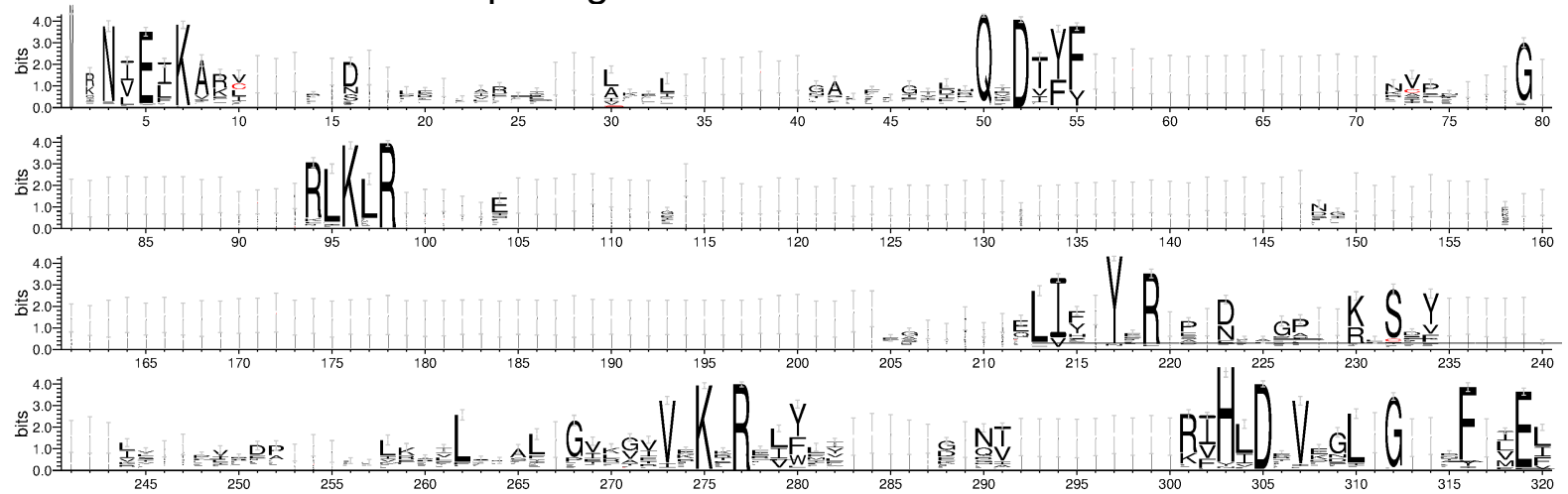

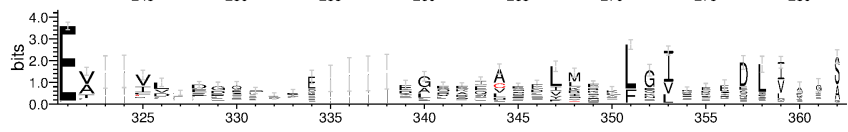

WEBLOGO Cluster 7 comprising 56 entries from 234 IDs within the SSN
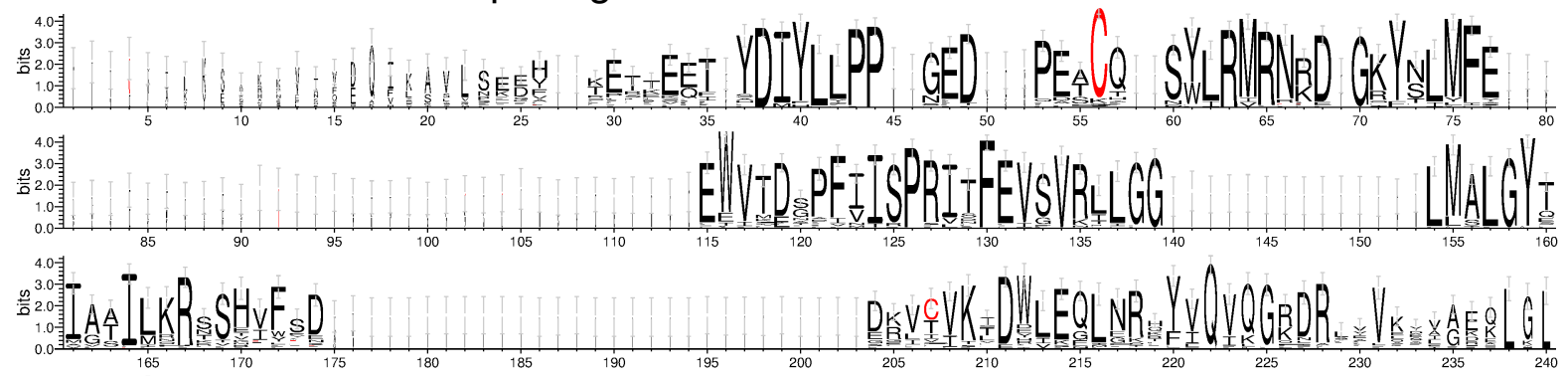

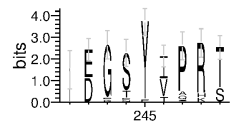


WEBLOGO Cluster 8 comprising 178 entries from 297 IDs within the SSN
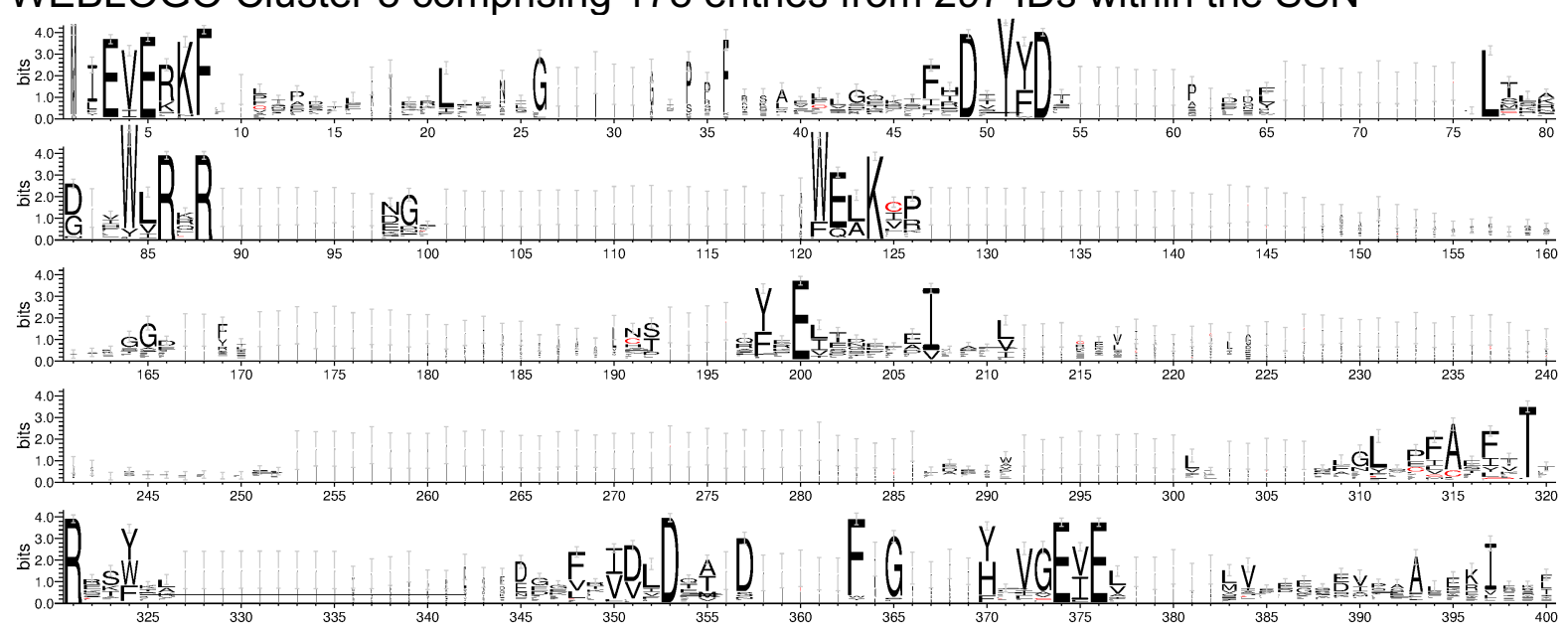

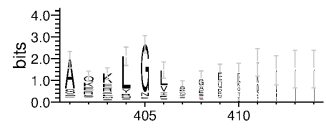

WEBLOGO Cluster 9 comprising 85 entries from 221 IDs within the SSN

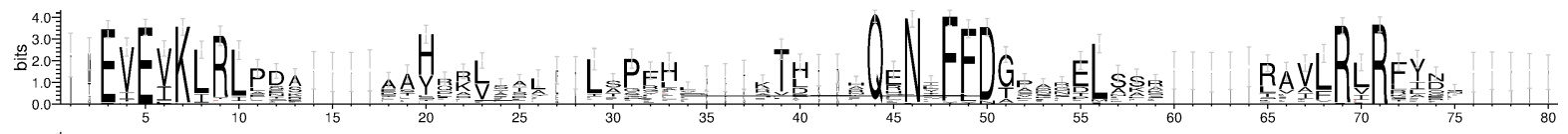

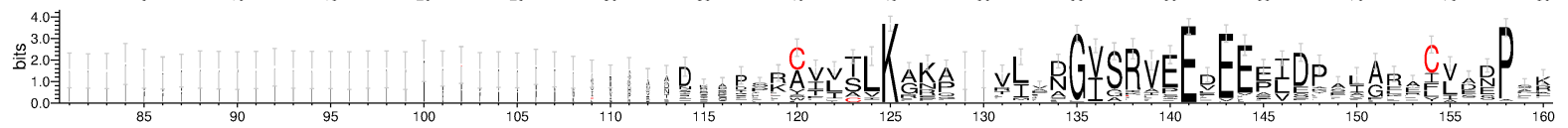

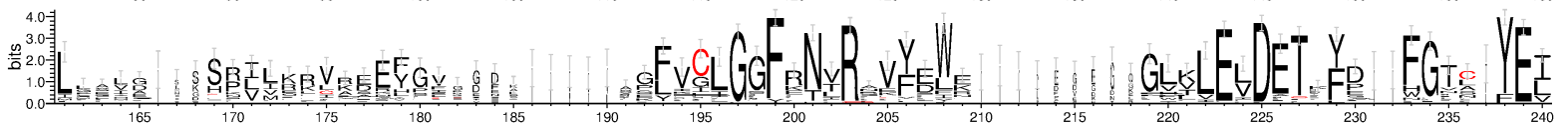

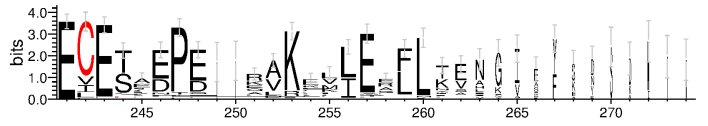

WEBLOGO Cluster 10 comprising 23 entries from 141 IDs within the SSN from the full length alignment, as the HF-motif exceeds the domain boundaries

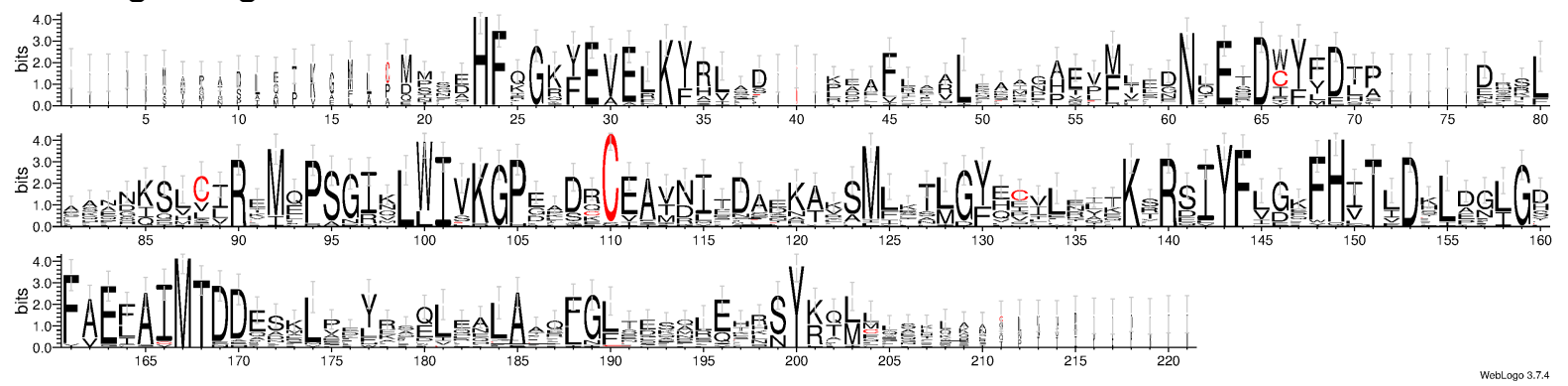




\section{Supplementary tables}

Table S1: Overview of characterized PF01928 enzymes. Coloring according to SSN.

\begin{tabular}{|c|c|c|c|c|c|c|c|c|}
\hline PDB & UNIPROT & ORGANISM & NAME & LIGAND/STATE/NOTES & MOTIFS & FUNCTION & SOURCE & CLUSTER \\
\hline $5 \mathrm{~A} 60$ & P30871 & E. coli & Ygif & $\mathrm{PPPi}+\mathrm{Mg}+\mathrm{Mg}$ & $\begin{array}{l}\text { ExExK, } \\
\text { GxRxR, ExE }\end{array}$ & TTM & Martinez et al (2015) & 1 \\
\hline $5 \mathrm{~A} 61$ & P30871 & E. coli & Ygif & $\mathrm{PPP} i+\mathrm{Mn}+\mathrm{Mn}$ & $\begin{array}{l}\text { ExExK, } \\
\text { GxRxR, ExE }\end{array}$ & TTM & Martinez et al (2015) & 1 \\
\hline \multirow[t]{2}{*}{$\begin{array}{l}\text { 2FBL, } \\
\text { 3TYP }\end{array}$} & Q82U19 & N. europaea & NeuTTM & empty, open & $\begin{array}{l}\text { ExExK, ExRxR, } \\
\text { ExE }\end{array}$ & TTM & Delvaux et al (2011) & 2 \\
\hline & A3DIJ8 & C. thermocellum & CthTTM & & $\begin{array}{l}\text { ExExK, SxRxR, } \\
\text { ExE }\end{array}$ & TTM & $\begin{array}{l}\text { Jain and Shuman } \\
\text { (2008) }\end{array}$ & 2 \\
\hline $2 \mathrm{DC} 4$ & O58740 & P. horikoshii & PhotTM & $3 \times \mathrm{Cl}-$ & $\begin{array}{l}\text { ExExK, LxRxR, } \\
\text { DxE }\end{array}$ & TTM & unpublished & 3 \\
\hline 2EEN & O59483 & P. horikoshii & PhotTM & empty & $\begin{array}{l}\text { ExExK, AxRxR, } \\
\text { ExE }\end{array}$ & TTM & unpublished & 3 \\
\hline 1YEM & Q8U2H2 & P. furiosus & PfTTM & UNK, density for PPPi & $\begin{array}{l}\text { ExExK, LxRxR, } \\
\text { DxE }\end{array}$ & TTM & unpublished & 3 \\
\hline $7 \mathrm{NS} 8$ & Q4JAT2 & S. acidocaldarius & SaTTM & $2 \times \mathrm{SO}_{4}$ & $\begin{array}{l}\text { ExExK, AxRxR, } \\
\text { ExE }\end{array}$ & TTM & This study & 3 \\
\hline $7 \mathrm{NSF}$ & Q4JAT2 & S. acidocaldarius & SaTTM & PPPi, Mg & $\begin{array}{l}\text { ExExK, AxRxR, } \\
\text { ExE }\end{array}$ & TTM & This study & 3 \\
\hline 7NS9 & Q4JAT2 & S. acidocaldarius & SaTTM & $\mathrm{PPPi}, 2 \times \mathrm{Ca}$ & $\begin{array}{l}\text { ExExK, AxRxR, } \\
\text { ExE }\end{array}$ & TTM & This study & 3 \\
\hline 7NSA & Q4JAT2 & S. acidocaldarius & SaTTM & $\mathrm{PPi}, \mathrm{Ca}$ & $\begin{array}{l}\text { ExExK, AxRxR, } \\
\text { ExE }\end{array}$ & TTM & This study & 3 \\
\hline $7 \mathrm{NSD}$ & Q4JAT2 & S. acidocaldarius & SaTTM & ATP, $2 \times \mathrm{Ca}$ & $\begin{array}{l}\text { ExExK, AxRxR, } \\
\text { ExE }\end{array}$ & TTM & This study & 3 \\
\hline $3 S Y 3$ & A0A1J9V1U0 & B. antharcis & & empty & $\begin{array}{l}\text { ExExK, AxRxR, } \\
\text { ExE }\end{array}$ & TTM & unpublished & 5 \\
\hline $3 \mathrm{TJ} 7$ & A0A1J9V1U0 & B. antharcis & & $\begin{array}{l}\text { empty, AMP stacked in } \\
\text { interface }\end{array}$ & $\begin{array}{l}\text { ExExK, AxRxR, } \\
\text { ExE }\end{array}$ & TTM & unpublished & 5 \\
\hline \multirow[t]{4}{*}{ 2GFG } & Q9K901 & B. halodurans & & UNL & $\begin{array}{l}\text { ExExK, AxRxR, } \\
\text { ExE }\end{array}$ & TTM & unpublished & 5 \\
\hline & $\mathrm{AOAOH} 2 \mathrm{XGCO}$ & S. aureus & SAUSA300_0905 & & $\begin{array}{l}\text { ExExK, AxRxR, } \\
\text { ExE }\end{array}$ & TTM & Zhang et al (2017) & 5 \\
\hline & Q9C9B9 & A. thaliana & AtTTM1 & & $\begin{array}{l}\text { no ExExK, } \\
\text { YMxRxR, no } \\
\text { ExE }\end{array}$ & PPase & Ung et al (2017) & 7 \\
\hline & Q9C664 & A. thaliana & AtTTM2 & & $\begin{array}{l}\text { no ExExK, } \\
\text { YMXRXR, no } \\
\text { ExE }\end{array}$ & PPase & Ung et al (2017) & 7 \\
\hline 3BHD & Q9BU02 & H. sapiens & HsThTPase & $\mathrm{SO} 4, \mathrm{CIT}, \mathrm{Cl}$ & $\begin{array}{l}\text { ExExK, } \\
\text { WxRxR, ExE }\end{array}$ & ThTPase & unpublished & 8 \\
\hline 3TVL & Q9BU02 & H. sapiens & HsThTPase & PPPi & $\begin{array}{l}\text { ExExK, } \\
\text { WxRxR, ExE }\end{array}$ & ThTPase & Delvaux et al (2013) & 8 \\
\hline 2JMU & Q8JZL3 & M. musculus & MmThTPase & empty (NMR) & $\begin{array}{l}\text { ExExK, } \\
\text { WxRxR, ExE }\end{array}$ & ThTPase & Martinez et al (2015) & 8 \\
\hline $5 A 64$ & Q8JZL3 & M. musculus & MmThTPase & $\begin{array}{l}\text { Thiaminetriphosphate } \\
\text { (water instead of M1 build, } \\
\text { small offset) }\end{array}$ & $\begin{array}{l}\text { ExExK, } \\
\text { WxRxR, ExE }\end{array}$ & ThTPase & Martinez et al (2015) & 8 \\
\hline 5 A65 & Q8JZL3 & M. musculus & MmThTPase & $\begin{array}{l}\text { Thiaminepyrophosphate } \\
+\mathrm{Pi}+2 \mathrm{Mg} 2\end{array}$ & $\begin{array}{l}\text { ExExK, } \\
\text { WxRxR, ExE }\end{array}$ & ThTPase & Martinez et al (2015) & 8 \\
\hline $3 \mathrm{~V} 85$ & Q9SIY3 & A. thaliana & АtТTM3 & $\mathrm{CIT}$ & $\begin{array}{l}\text { ExExK, VxRxR, } \\
\text { ExE }\end{array}$ & TTM & unpublished & 9 \\
\hline $5 A 5 Y$ & Q9SIY3 & A. thaliana & АtТTM3 & PPPi, Mg & $\begin{array}{l}\text { ExExK, VxRxR, } \\
\text { ExE }\end{array}$ & TTM & Martinez et al (2015) & 9 \\
\hline 5 A66 & Q9SIY3 & A. thaliana & АtТTM3 & PPPi, Mn & $\begin{array}{l}\text { ExExK, VxRxR, } \\
\text { ExE }\end{array}$ & TTM & Martinez et al (2015) & 9 \\
\hline $5 \mathrm{~A} 67$ & Q9SIY3 & A. thaliana & АtТTM3 & PPPi, Mn & $\begin{array}{l}\text { ExExK, VxRxR, } \\
\text { ExE }\end{array}$ & TTM & Martinez et al (2015) & 9 \\
\hline \multirow[t]{2}{*}{$5 \mathrm{~A} 68$} & Q9SIY3 & A. thaliana & АtТTM3 & $2 \times \mathrm{Pi}, 3 \times \mathrm{Mn}$ & $\begin{array}{l}\text { ExExK, VxRxR, } \\
\text { ExE }\end{array}$ & TTM & Martinez et al (2015) & 9 \\
\hline & |1112P2 & B. distachyon & ВवтTM3 & & $\begin{array}{l}\text { ExExK, AxRxR, } \\
\text { ExE }\end{array}$ & $\begin{array}{l}\text { TTM } \\
\text { (shown is } \\
\text { also low } \\
\text { AC) }\end{array}$ & $\begin{array}{l}\text { Swiezawska et al } \\
(2020)\end{array}$ & 9 \\
\hline 6YP4 & E1AQY1 & H. hybrid cultivar & HpAC1 & $\begin{array}{l}\mathrm{GCP}, 2 \times \mathrm{Mg} \text {, metals not } \\
\text { coordinated the usual way, } \\
\text { nucleotides from two } \\
\text { protomers are stacked }\end{array}$ & $\begin{array}{l}\text { ExExK, AxRxR, } \\
\text { ExE }\end{array}$ & $\begin{array}{l}\text { TTM, no } \\
\text { measurable } \\
\text { AC activity }\end{array}$ & $\begin{array}{l}\text { Kleinboelting et al } \\
(2020)\end{array}$ & 9 \\
\hline 2FJT & A0A384LKY8 & Y. pestis & СуаВ & empty & $\begin{array}{l}\text { HFxxxxExExK, } \\
\text { SxVxR, ExA }\end{array}$ & $A C$ & $\begin{array}{l}\text { Gallagher et al } \\
(2006)\end{array}$ & 10 \\
\hline $3 \mathrm{NOY}$ & A0A384LKY8 & Y. pestis & Суав & AMPCPP $+M n$ & $\begin{array}{l}\text { HFxxxxExExK, } \\
\text { SxVxR, ExA }\end{array}$ & $A C$ & $\begin{array}{l}\text { Gallagher et al } \\
\text { (2011) }\end{array}$ & 10 \\
\hline $3 \mathrm{NOZ}$ & A0A384LKY8 & Y. pestis & СуаВ & $3 A T+M n$ & $\begin{array}{l}\text { HFxxxxExExK, } \\
\text { SxVxR, ExA }\end{array}$ & $A C$ & $\begin{array}{l}\text { Gallagher et al } \\
\text { (2011) }\end{array}$ & 10 \\
\hline 3N10 & A0A384LKY8 & Y. pestis & СуaВ & $\mathrm{cAMP}+\mathrm{Mn}+\mathrm{Mn}$ & $\begin{array}{l}\text { HFxxxxExExK, } \\
\text { SxVxR, ExA }\end{array}$ & $A C$ & $\begin{array}{l}\text { Gallagher et al } \\
\text { (2011) }\end{array}$ & 10 \\
\hline $2 \mathrm{ACA}$ & Q87NV8 & $\begin{array}{l}V \text {. } \\
\text { parahaemolyticus }\end{array}$ & & $2 \times \mathrm{PO} 4$ & $\begin{array}{l}\text { HFxxxxExExK, } \\
\text { IxRxV, ExA }\end{array}$ & $A C$ & unpublished & 10 \\
\hline
\end{tabular}


Table S2: Data collection and refinement statistics

\begin{tabular}{|c|c|c|c|c|c|}
\hline SaTTM & relaxed/SOH & $\mathrm{PPPi} / \mathrm{Ca}^{2+}$ & PPPi/Mg ${ }^{2+}$ & $\mathrm{PPi} / \mathrm{Ca}^{2+}$ & ATP $/ \mathrm{Ca}^{2+}$ \\
\hline $\begin{array}{l}\text { PDB code } \\
\text { Data collection }\end{array}$ & \multicolumn{4}{|c|}{ Data collection } & 7NSD \\
\hline Synchrotron beamline & ESRF ID29 & ESRF ID29 & ESRF ID23-1 & ESRF ID30B & ESRF ID29 \\
\hline Wavelength $(\AA)$ & 0.979 & 0.979 & 0.972 & 0.976 & 0.979 \\
\hline Resolution range $(\AA)$ & $44.4-2.3(2.38-2.30)$ & $46.0-1.75(1.81-1.75)$ & $43.2-2.0(2.07-2.0)$ & $46.0-1.95(2.02-1.95)$ & $45.8-2.2(2.27-2.19)$ \\
\hline Space group & $P 41212$ & $P 41212$ & $P 41212$ & $P 41212$ & $P 41212$ \\
\hline Unit cell $\left(\AA,{ }^{\circ}\right)$ & $\begin{array}{l}57.66,57.66,139.15 \\
90,90,90\end{array}$ & $\begin{array}{l}60.67,60.67,141.09 \\
90,90,90\end{array}$ & $\begin{array}{l}61.0,61.03,136.62 \\
90,90,90\end{array}$ & $\begin{array}{l}60.55,60.55,141.63 \\
90,90,90\end{array}$ & $\begin{array}{l}60.67,60.67,139.35 \\
90,90,90\end{array}$ \\
\hline Total reflections & $22129(2148)$ & $51470(5143)$ & $36416(3558)$ & 38954 (3885) & $28144(2738)$ \\
\hline Unique reflections & $11068(1074)$ & $25885(2581)$ & $18208(1778)$ & 19769 (1955) & $14072(1367)$ \\
\hline Multiplicity & $2.0(2.0)$ & $2.0(2.0)$ & $2.0(2.0)$ & $2.0(2.0)$ & $2.0(2.0)$ \\
\hline Completeness (\%) & $99.95(100.00)$ & $94.31(96.81)$ & $98.92(99.94)$ & $98.87(99.69)$ & $99.95(99.78)$ \\
\hline Mean $I / \sigma(I)$ & $29.77(15.39)$ & $11.44(2.12)$ & $17.55(2.43)$ & $16.60(2.65)$ & $17.15(4.12)$ \\
\hline Wilson B-factor $\left(\AA^{2}\right)$ & 34.52 & 32.86 & 43.90 & 37.37 & 48.39 \\
\hline Rmerge & $0.01(0.04)$ & $0.02(0.30)$ & $0.01(0.26)$ & $0.02(0.27)$ & $0.01(0.17)$ \\
\hline Rmeas & $0.02(0.06)$ & $0.03(0.41)$ & $0.02(0.37)$ & $0.03(0.38)$ & $0.02(0.24)$ \\
\hline $\mathrm{CC} 1 / 2$ & $1(0.99)$ & $1(0.35)$ & $1(0.88)$ & $1(0.73)$ & $1(0.86)$ \\
\hline \multicolumn{6}{|l|}{ Refinement statistics } \\
\hline Resolution range $(\AA)$ & $44.4-2.3$ & $46.0-1.75$ & $43.2-2.0$ & $46.0-1.95$ & $45.8-2.2$ \\
\hline$R_{\text {work }} / R_{\text {free }}(\%)$ & $22.6 / 25.7$ & $18.9 / 23.5$ & $20.7 / 23.9$ & $22.5 / 24.6$ & $22.4 / 25.3$ \\
\hline Average B-factor $\left(\AA^{2}\right)$ & 41.38 & 51.48 & 59.86 & 47.2 & 63.42 \\
\hline No. of atoms & 1476 & 1641 & 1607 & 1619 & 1572 \\
\hline macromolecules & 1341 & 1477 & 1479 & 1465 & 1455 \\
\hline ligands & 24 & 26 & 14 & 27 & 37 \\
\hline solvent & 111 & 138 & 114 & 127 & 80 \\
\hline R.m.s.d., (bonds. Â) & 0.010 & 0.007 & 0.008 & 0.018 & 0.011 \\
\hline & 1.15 & 0.73 & 1.09 & 1.93 & 1.48 \\
\hline \multicolumn{6}{|l|}{ Ramachandran plot } \\
\hline favored (\%) & 97.44 & 97.16 & 97.71 & 97.69 & 96.55 \\
\hline allowed (\%) & 2.56 & 2.84 & 2.29 & 2.31 & 3.45 \\
\hline outliers (\%) & 0.00 & 0.00 & 0.00 & 0.00 & 0.00 \\
\hline Rotamer outliers (\%) & 2.05 & 0.62 & 0.62 & 2.47 & 0.00 \\
\hline Clashscore & 3.68 & 1.34 & 3.70 & 4.00 & 3.04 \\
\hline
\end{tabular}

